\title{
Optical Characterization in Microelectronics Manufacturing
}

\section{S. Perkowitz ${ }^{1}$ and D. G. Seiler \\ National Institute of Standards and Technology, Gaithersburg, MD 20899-0001}

\section{and}

\section{W. M. Duncan}

Texas Instruments, Inc., Dallas, TX 75243
To successfully construct semiconductor devices, the semiconductor industry must measure fundamental material parameters, especially when developing new materials; measure the quality of the matcrial as it is grown; accurately determine the details of thin films, quantum wells, and other microstructures that control or affect device performance; and measure properties of the devices themselves. Properties that need to be determined, therefore, include basic band structure and transport parameters, such as energy gap values and carrier scattering times; the presence and concentration of impurities and defects; alloy parameters; layer thicknesses; the distribution of materials in complex structures; and many others. This process of determining a wide range of material, structural, and device parameters is ealled characterization. The semiconductor industry uses many characterization methods which draw on electrical, chemical, and other approaches. Among these, optical characterization techniques, defined as those using electromagnetic radiation from the ultraviolet to the far infrared, stand out because they are nondestructive and require minimal sample preparation since no contacts are needed. These features are of great importance for production use or to examine finished devices. Another benefit is that, unlike electrical methods which require fixed contacts, optical techniques can give two- or three-dimensional maps of properties over the extent of a semiconductor wafer. The six techniques de. scribed in this paper (ellipsometry, infrared spectroscopy, microscopy, modulation spectroscopy, photoluminescence, and Raman scattering) were chosen beeause they are currently or potentially widely used in the industry; they measure a broad array of semiconductor parameters; and they operate in different regions of the electromagnetic spectrum. The discussion of each technique indicates the basic semiconductor quantities measured, gives the scientific basis of the technique, and indicates how the measurement is made. Illustrative examples from the literature are discussed in detail, showing applications to important semiconductor materials. More information can be obtained from the detailed list of references included.

Key words: ellipsometry; infrared spectroscopy; modulation spectroscopy; optical microscopy; photoluminescence; Raman scattering.

Accepted: July 21, 1994

\section{Contents}

1. Introduction $\ldots \ldots \ldots \ldots \ldots \ldots \ldots . \ldots \ldots$

2. Ellipsometry................ 607

\footnotetext{
${ }^{1}$ Consulting seientist. Present address: Department of Plyysics, Rollins Researeh Center, Emory University, Atlanta, GA 303222430.
}

3. Infrared Spectroscopy........... 612

4. Optical Microscopy............. 617

5. Modulation Spectroscopy.......... 623

6. Photoluminescence ............. 627

7. Raman Scattering ............ 634 


\section{Introduction}

To successfully construct semiconductor devices, the microelectronics industry must measure fundamental material parameters, especially when developing new materials; measure the quality of the material as it is grown; accurately determine the structural details of thin films, quantum wells, and other microstructures at the heart of devices; and measure properties of the devices themselves. Properties that need to be determined, therefore, include basic band structure and transport parameters, such as gap values and carrier scattering times, the presence and concentration of impurities and defects, alloy parameters, layer thicknesses, the distribution of materials in complex structures, and many others.

The semiconductor industry uses many characterization methods which draw on electrical, chemical, and other approaches. Among these, optical characterization techniques, defined as those using electromagnetic radiation from the ultraviolet to the far infrared, stand out because they are nondestructive and require minimal sample preparation, since no contacts are needed. These features are of great importance for production use, for on-line applications, and for examination of finished devices. Another benefit is that optical techniques can give two- or three-dimensional maps of properties over the extent of a semiconductor wafer without requiring fixed contacts.

Six techniques are described in this paper (ellipsometry, infrared spectroscopy, optical microscopy, modulation spectroscopy, photoluminescence, and Raman scattering). They were chosen because they are currently widely used in the industry and because they measure a broad array of semiconductor parameters. The discussion of each technique indicates the basic semiconductor quantities measured (see Table 1), the physical basis of the technique, and how the measurement is made. Illustrative examples from the literature are discussed, showing applications to important semiconductor material systems. A more detailed review of infrared, Raman and photoluminescence spectroscopies is given in a book by Perkowitz [1]. A recent review of the optical properties of semiconductors is given by Amirtharaj and Seiler [2].

\subsection{A Note on Units}

Some regions of the electromagnetic spectrum, and some optical methods, refer to wavelength as a matter of usage; others use wavenumbers, or photon energy. Each section here uses the most common units for that technique, including wavelength in nanometers $(\mathrm{nm})$ and micrometers $(\mu \mathrm{m})$; wavenumber in $\mathrm{cm}^{-1}$; and photon energy in electron volts $(\mathrm{eV})$. Table 2 shows conversion factors for the main units of measure usually encountered.

Table 1. Semieonductor quantities (horizontal rows) and optical characterization methods (vertical columns, labeled as follows: ELL, ellipsometry; IR, infrared spectroscopy; MIC, microscopy; MOD, modulation spectroscopy; PL, photoluminesecnec; and RAM, Raman scattering). A bullet at the intersection of a given row and column means that the parameter can be determined by that technique using conventional methodology. Further details are given in the diseussion

\begin{tabular}{|c|c|c|c|c|c|c|}
\hline & ELL & IR & MIC & MOD & PL & RAM \\
\hline Carrier density & - a & & & & $\bullet$ & \\
\hline Carrier mobility & & $\bullet$ & & & & $\bullet$ \\
\hline $\begin{array}{l}\text { Carrier scattering } \\
\text { time }\end{array}$ & - & & & $\cdot b$ & & \\
\hline Composition & - & - & - & $\bullet$ & $\bullet$ & - \\
\hline Crystal orientation & & & & & & - \\
\hline Crystallinity & - & $\bullet$ & & & $\bullet$ & $\bullet$ \\
\hline Defects & & - & - & & $\bullet$ & - \\
\hline Energy gap & & - & & $\bullet$ & - & \\
\hline Film thickncss & - & $\bullet$ & - & & & \\
\hline Inpurities & & $\bullet$ & - & $\bullet$ & $\bullet$ & $\cdot$ \\
\hline Resistivity & & $\bullet$ & & & & - \\
\hline Stress & - & - & & - & - & $\bullet$ \\
\hline
\end{tabular}

"If the effective mass is known.

b Time resolved.

Table 2. Conversion factors for units of measurc

$\begin{aligned} & =10^{3} \lambda / \mu \mathrm{m} \\ E_{\lambda} / \mathrm{eV} & =1.2397 /(\lambda / \mu \mathrm{m}) \\ & =1.2397 \times 10^{-4} \lambda^{-1} / \mathrm{cm}^{-1} \\ \lambda^{-1} / \mathrm{cm}^{-1} & =10^{4} /(\lambda / \mu \mathrm{m})\end{aligned}$

\subsection{References}

[1] S. Perkowitz, Optieal Charaeterization of Semiconductors: Infrared, Raman, and Photoluminescence Spectroseopy, Academie Press, London (1993).

[2] P. Amirtharaj and D. G. Sciler, Optical Properties of Semiconductors, Chapter in Handbook of Optics, McGraw-Hill, to be published. 


\section{Ellipsometry}

\subsection{Introduction}

Ellipsometry is a technique widely used to measure the thicknesses of films important to semieonductor technology, such as $\mathrm{SiO}_{2}$ on $\mathrm{Si}$. Thieknesses measured are typically in the range of several $\mathrm{nm}$ to several hundred $\mathrm{nm}$. Surface cleanliness of semiconductor wafers during processing can also be determined. In spectroscopic ellipsometry, the ellipsometric data are obtained as a function of wavelength. Then appropriate modeling and fitting can yield the dielectric functions and thieknesses of the layers in complex semiconductor/oxide multilayer systems, such as SIMOX (Separation by IMplanted OXygen), a silicon-on-insulator material formed by high-energy oxygen ion implantation in silicon. The dielectric functions give a complete picture of composition for the entire layered strueture.

\subsection{Physical Basis}

Ellipsometry is based on the polarization transformation that occurs when a beam of polarized light is reflected from (or transmitted through) an interface or film. For example, if plane- or linearlypolarized light impinges on the surface of an absorbing medium, the reflected light usually beeomes elliptically polarized because the reflection proeess differently affects the in-plane component of the incident electric field $E_{\mathrm{p}}$, relative to the perpendieular electric field component $E_{\mathrm{s}}$. Eaeh component is reflected with new values of amplitude and phase. The key parameters obtained from an ellipsometric measurement are the ellipsometrie angles $\psi$ and $\Delta$. These appear in the complex refleetion ratio $\rho$, defined as

$$
\rho=\frac{r_{\mathrm{p}}}{r_{\mathrm{s}}}=\tan (\psi) \mathrm{e}^{i \Delta},
$$

where the amplitude reflection coeffieients $r_{p}$ and $r_{\mathrm{s}}$ are

$$
\begin{aligned}
& r_{\mathrm{p}}=\frac{E_{\mathrm{p}}(\text { reflected })}{E_{\mathrm{p}}(\text { incident })} \\
& r_{\mathrm{s}}=\frac{E_{\mathrm{s}}(\text { reflected })}{E_{\mathrm{s}}(\text { inciden })} .
\end{aligned}
$$

The ellipsometric angles are defined as $\psi=\tan ^{-1}|\rho|$, and $\Delta$ is the difference in phase between the $\mathrm{p}$ and $\mathrm{s}$ components.

\subsection{Experimental and Teclonical Detials}

Ellipsometric measurements stirt with light of known polarization ineident on the sample. Whe polarization of the refleeted light is determined, from whieh further analysis gives the parameters such as refraetive index and film thickness which determine the interaetion between light and sample.

In its simplest form, single-watvelengili ellipsontetry requires a manual nulling to gather data. light from the source (usually a laser for single-wivelength work) passes through a linear polarizer, then through a compensator which ellipticilly polarizes the light. The light eontinues to the sample, is refleeted, passes through a polirization analyzer, and is finally detected. The null technigue works by arljusting the angle of the polarizer with respect to eompensator, sample, and analyzer until the rellec. tion process just eancels the ellipticity the light gained from the eompensator. Then the reflected light is linearly polarized and can be extinguislicel by ehoosing the appropriate angle for the analyzer. that is, until the photomultiplicr shows a minimum signal. The two values of the angles yicld $\rho$.

This null process is too slow for real-time measurements, or for spectroscopic cllipsometry. Three types of automatic ellipsometry (self-eompersating. rotating element, and polarization-modulated), (o)gether with dedieated computers, allow rapid me:s. surement and analysis. In the automatic self-compensating system [1], the angles of the lin. early polarized light leaving the polarizer, and en. tering the amalyzer, are rotated by latraday or Pockels cells, until the null is achieved. This type of instrument ean give fixed wavelength data within I $\mathrm{ms}$, and spectroscopic data over a wide wavelength range in $3 \mathrm{~s}$.

The optical layout of the rotating elentent system (Fig. 1) is like that of the self-compensating system with the compensitor omitted [1]. The polarization analyzer rotates around the avis of the reflected light beam at a fixed angular velocity, typically cor. responding to $50 \mathrm{~Hz}$ to $100 \mathrm{~Hz}$. The rolating anat bzer would produce a sine-squared signal with two maxima and two true zero minima every lotation, if the light were linearly polarized. For elliptically polarized light, the signal is also of sine-squancel form, but with smaller maxima, and nonzero min. ima, which depend on the ellipticity of the reflected light. A Fourier analysis of the output of the rotat. ing analyzer gives $\rho$ and hence the angles $b$ and $J$. For an analyzer rotating at $1001 \%$. The measuse. ment at a single wavelength ean he eompleted in $5 \mathrm{~ms}$. 


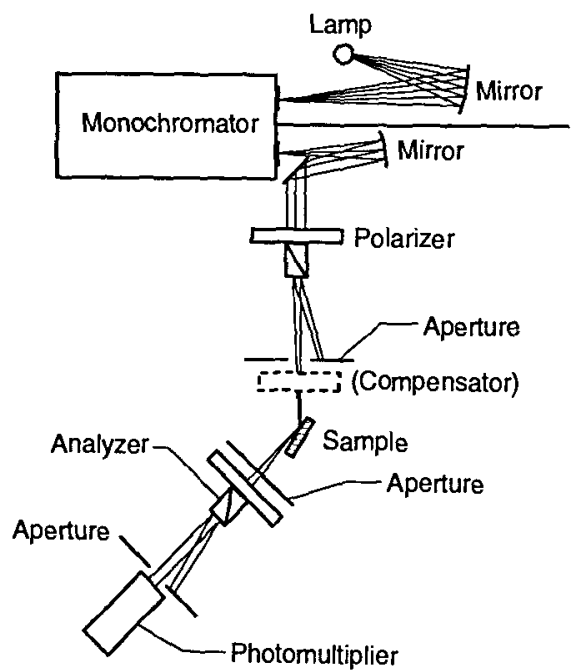

(a)

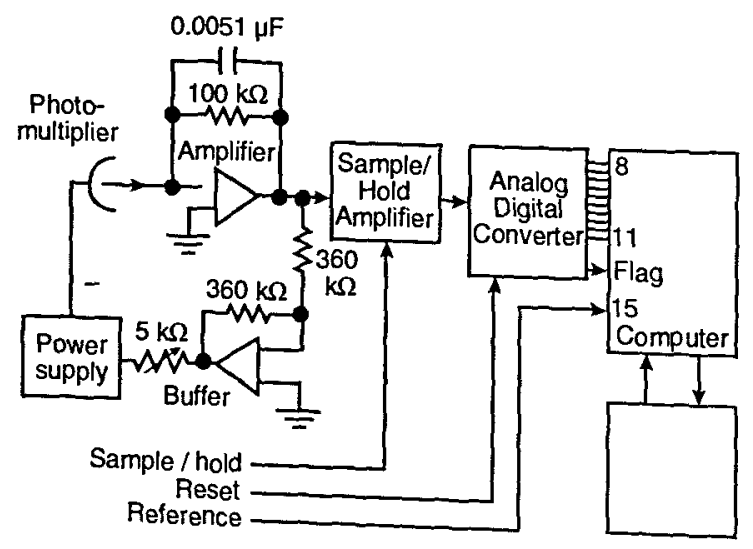

(b)

Fig. 1. Schemalie diagrams of (a) oplical elements and (b) signal processing system for a rolaling analyzer spectroscopie ellipsometer designed for high-precision measurements of the optieal properties of solids. (See See. 2.5, General Refs., Collins (1990),
fig. 3, p. 2032.)

The fastest type of system is the polarizationmodulated ellipsometer [1], where the compensator in the manual null system is replaced by a birefringent phase modulator (a piezobirefringent plate or a Pockels cell). In the phase modulator, the ellipticity imparted to the linearly polarized light varies sinusoidally with time, rather than remaining constant as in the self-compensating system. The signal which results at the detector can be Fourier analyzed or analyzed by a phase-sensitive detector to give $\rho$. A piezobirefringent modulator is a fast device, which can operate at $100 \mathrm{kHz}$ or more; hence, this system can obtain data in an interval of $10 \mathrm{~ms}$ per wavelength measurement, which means that full scans over the range $400 \mathrm{~nm}$ to $700 \mathrm{~nm}$ can be obtained in a few seconds or less.

Of the three automatic systems, the polarizationmodulated spectrometer is best for real-time rapid data acquisition. However, in the self-compensating and polarization-modulation cases, the compensator or modulator must be tuned for each wavelength; hence, these are more complex and can be less accurate than the rotating analyzer system.

For spectroscopic ellipsometry, a stable xenon lamp with output covering the near ultraviolet to near infrared is a commonly used source. The sample is mounted on a high-accuracy stage to allow careful angle alignment. Usually an autocollimator and apertures are used to control collimation and alignment. In general, available equipment gives good results over the near infrared to the near ultraviolet. The ellipsometric angles $\Delta$ and $\psi$ can be measured to within millidegrees, resulting in uncertainties of less than one part in $10^{3}$ for the index of refraction and tenths of a nanometer for the corresponding thicknesses.

Parameters for a complex semiconductor/oxide system examined by ellipsometry are determined by sophisticated computer software [1-2]. These fit the measured ellipsometric parameters versus wavelength, by assuming appropriate dielectric functions for each layer, and layer thicknesses. Commercial systems include appropriate software, and fitting routines are also available from other sources.

\subsection{Illustrative Applications}

An example of the kind of semiconductor analysis that can be achieved with spectroscopic ellipsometry is shown in Fig. 2 for a sample of SIMOX, an important silicon-on-insulator system. The ellipsometric angles $\Delta$ and $\psi$ show complex spectra over the range $1.5 \mathrm{eV}$ to $4.5 \mathrm{eV}$, with the large oscillations related to interference effects. Multiparameter regression analysis yields the fits displayed in the plots, which determine the sample's structural details as shown.

Table 3 presents typical sensitivities of quantities obtained by ellipsometry, such as thicknesses, composition, and temperature. For more specific details, the reader can refer to the citations given in the table. 


\section{Sample \#802}

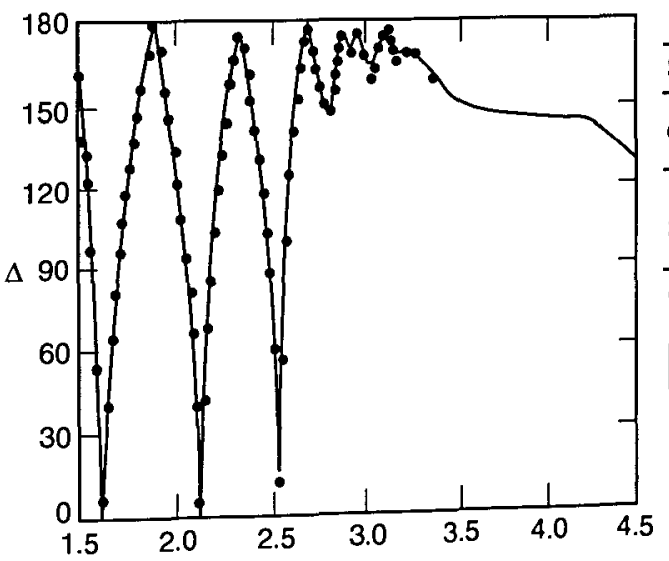

$$
\begin{array}{cr}
\overline{\mathrm{SiO}_{2}} & (14.0 \pm 0.3) \AA \\
\hline \mathrm{c}-\mathrm{Si} & (2288 \pm 0.2) \AA
\end{array}
$$

$\mathrm{SiO}_{2} \quad(3340 \pm 28) \mathrm{A}$

$\mathrm{c}-\mathrm{Si} / \mathrm{SiO}_{2}(306 \pm 10) \mathrm{A}$

$0.47 \pm 0.03$
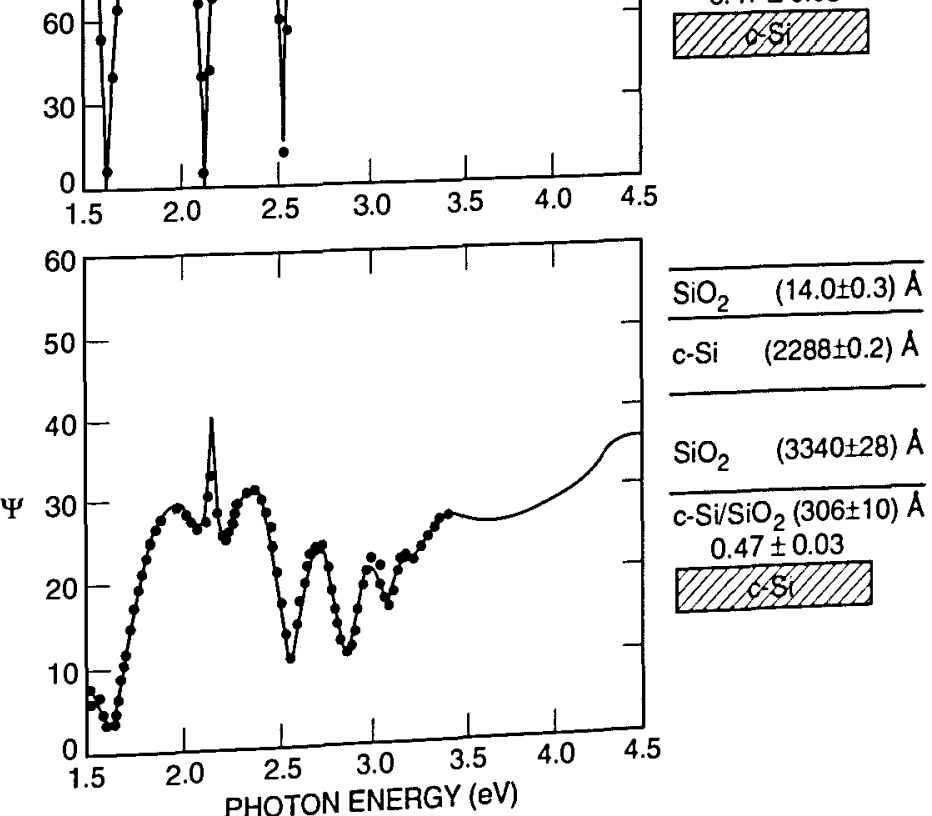

Fig. 2. Ellipsometric angles $\Delta$ and $\psi$ versus photon energy for a SIMOX sample. Individual points, data obtained from rotating element spectroscopic cllipsometer. Solid line, fit obtained by regression analysis assuming structura la $334 \mathrm{~nm} \mathrm{SiO}$ layer

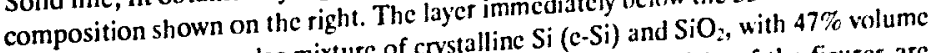
is modeled as a granular mixture of crystalline Si (c-Si) and the right of the figures are fraction c-Si, using effective medium theory. Shewn the thicknesses of the layers. The calculated uncert by the regresion analysis. (After are set to one standard deviation as detcrmined by the National Institute of Stan. D. Chandler-Horowitz et dards and Technology.) 
Table 3. Spectral ellipsometry sensitivity. Given are sensitivities for the measurement of thickncsses, composition, damage profile, and tcmperature in a number of systems. The notations used for the measured quantity column are the complex reflection ratio, $\rho$; the amplitude ratio, $\psi$; and the phase shift, $\Delta$

\begin{tabular}{|c|c|c|c|c|c|c|}
\hline Method & Matrix & Quantity & $\begin{array}{l}\text { Measured } \\
\text { quantity }\end{array}$ & Conversion & Sensitivitya & $\begin{array}{l}\text { Ref. } \\
\text { (see } \\
\text { below) }\end{array}$ \\
\hline $\mathrm{SE}$ & $\mathrm{SiO}_{2} / \mathrm{Si}$ & $\mathrm{SiO}_{2}$ thickness & $\rho$ & $\begin{array}{l}\text { Frcsnel Equations }{ }^{[1]} \\
\text { and Estimator }{ }^{[2]} \\
(F E \& E)\end{array}$ & $\begin{array}{l} \pm 0.2 \AA \text { to } \pm 0.6 \AA \\
@ 1000 \AA \text { to } 2300 \AA\end{array}$ & 3 \\
\hline SE & $\mathrm{SiO}_{2} / \mathrm{SiO}_{2}+\mathrm{Si} / \mathrm{Si}$ & $\begin{array}{l}\text { Interfacial } \\
\mathrm{SiO}_{2}+\mathrm{Si} \\
\text { thickness }\end{array}$ & $\rho$ & $\begin{array}{c}\text { FE\&E } \\
\text { and } \text { EMA }^{[4]}\end{array}$ & $\pm 2 \AA @ 7 \AA$ & 4 \\
\hline SE & $\mathrm{SiO}_{2} / \mathrm{SiO}_{2}+\mathrm{Si} / \mathrm{Si}$ & $\mathrm{SiO}_{2}$ thickness & $\rho$ & $\begin{array}{c}\text { FE\&E } \\
\text { and EMA }\end{array}$ & $\begin{array}{c}(1112.1 \pm 0.2) \AA \text { and } \\
(276.9 \pm 0.2) \AA\end{array}$ & 5 \\
\hline SE & $\mathrm{SiO}_{2} / \mathrm{a}-\mathrm{Si} / \mathrm{c}-\mathrm{Si}+\mathrm{SiC} / \mathrm{SiC} / \mathrm{c}-\mathrm{Si}$ & $\begin{array}{l}\text { Layer } \\
\text { thicknesses }\end{array}$ & $\rho$ & FE\&E and EMA & $\pm 2 \AA$ to $\pm 25 \AA$ & 6 \\
\hline SE & Polysilicon & $\begin{array}{l}\text { Polysilicon } \\
\text { composition } \\
\text { (e.g., void }+ \\
\text { c-Si }+ \text { a-Si) }\end{array}$ & $\rho$ & FE\&E and EMA & $\begin{array}{ll}\text { c-Si: } & 0.14 \pm 0.02 \\
\text { void: } & 0.25 \pm 0.06\end{array}$ & 7 \\
\hline SE & $\mathrm{Si}$ & Damage profile & $\rho$ & FE\&E and EMA & $\begin{array}{c}\text { Damage range } \\
(170 \pm 50) \AA \text { to } \\
(320 \pm 20) \AA\end{array}$ & 8 \\
\hline SE & $\mathrm{SiO}_{2} /$ polysilicon $/ \mathrm{SiO}_{2} / \mathrm{Si}$ & $\begin{array}{l}\text { Polysilicon and } \\
\mathrm{SiO}_{2} \\
\text { thicknesses }\end{array}$ & $\rho$ & FE\&E and EMA & $\begin{array}{l}\text { Native oxide }(15 \pm 0.3) \AA \\
\text { Poly } \pm 0.3 \AA \text { to } \pm 3.9 \AA \\
@(240 \text { to } 1030) \AA ; \\
\text { Oxide } \pm 0.4 \AA \text { to } \pm 1.7 \AA \\
\text { @ }(50 \text { to } 130) \AA\end{array}$ & 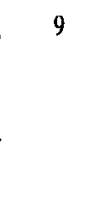 \\
\hline SE & $\mathrm{SiO}_{2} / \mathrm{Si} / \mathrm{SiN} / \mathrm{Si}$ & $\begin{array}{l}\text { Native oxide, } \\
\text { Si, and nitride } \\
\text { thickness }\end{array}$ & $\rho$ & FE\&E and EMA & - & 10 \\
\hline SWE & $\mathrm{SiO}_{2} / \mathrm{Si}$ & Temperature & $\psi, \Delta$ & polynomial & $\pm 10^{\circ} \mathrm{C}$ & 11 \\
\hline VASE & $\begin{array}{c}\text { Oxide/GaAs/ } \\
\mathrm{Al}_{x} \mathrm{Ga}_{1-x} \mathrm{As} / \\
\text { GaAs }\end{array}$ & $\begin{array}{l}\text { Thicknesses } \\
\text { and AlGaAs } \\
\text { composition }\end{array}$ & $\rho$ & FE\&E and EMA & $\begin{array}{c}\text { Oxide }(34 \pm 3) \AA \\
\text { GaAs }(159 \pm 8) \AA \\
\text { AlGaAs }(865 \pm 14) \AA \\
\text { AlGaAs, } x=0.35 \pm 0.02\end{array}$ & 12 \\
\hline VASE & $\begin{array}{c}\text { Oxide/GaAs/ } \\
\mathrm{Al}_{x} \mathrm{Ga}_{1-x} \mathrm{As} / \\
\mathrm{GaAs} / \mathrm{Al}_{x} \mathrm{GaAs}_{1-x} / \mathrm{GaAs}\end{array}$ & $\begin{array}{l}\text { Thicknesses } \\
\text { and AlGaAs } \\
\text { composition }\end{array}$ & $\rho$ & FE\&E and EMA & $\begin{array}{c}\text { Oxide }(26 \pm 1) \AA \\
\text { GaAs }(435 \pm 8) \AA \\
\text { AlGaAs }(413 \pm 14) \AA \\
\text { AlGaAs, } x=0.37 \pm 0.005 \\
\text { GaAs }(142 \pm 10) \AA \\
\text { AlGaAs/GaAs SLS } \\
5 @(470 \pm 20) \AA \\
\text { AlGaAs/GaAs SLS } \\
x=0.32 \pm 0.001\end{array}$ & 13 \\
\hline $\mathrm{SE}$ & $\mathrm{Al}_{2} \mathrm{Ga}_{1-} \mathrm{As} / \mathrm{GaAs}$ & $\begin{array}{c}\text { AlGaAs } \\
\text { composition } \\
\text { and thickness } \\
\text { in silu }\end{array}$ & $\rho$ & $\begin{array}{c}\text { Trajectories in } \epsilon_{1} \\
\text { and } \epsilon_{2}\end{array}$ & $\begin{array}{c}x=0.2 \pm 0.03 \\
(x>0.2)\end{array}$ & 14 \\
\hline
\end{tabular}

\footnotetext{
- Typically calculated as the $90 \%$ eonfidenee interval from the mean square deviation and covarianec matrix.

\section{References}

[1] R. M. A. Azzam and N. M. Bashara, Ellipsometry and Polarized Light, North Holland, Amsterdam (1989) Ch. 4.
[2] D. E. Aspncs, J. B. The

[2] D. E. Aspnes, J. B. Theeten, and R. P. H. Chang, J. Vae. Sei. Technol. 16, 1374 (1979).
} 
References to Table 3-Continued

[3] B. J. Mrstik, P. J. McMarr, J. R. Blanco, and J. M. Bennett, J. Electrochem. Soc. 138, 1770 (1991).

[4] D. E. Aspres and J. B. Theeten, J. Electrochem. Soc. 127, 1359 (1980).

[5] G. E. Jellison, Jr., J. Appl. Phys. 69, 7627 (1991).

[6] N. V. Nguyen and K. Vedam, J. Appl. Phys. 67, 3555 (1990).

[7] D. E. Aspnes, J. Vac. Sci. Technol. 18, 289 (1981).

[8] M. Fried, T. Lohner, W. A. M. Aarnink, L. J. Hanekamp, and A. van Silfhout, J. Appl. Phys. 71, 2835 (1992).

[9] W. M. Duncan and S. A. Henck, Appl. Surf. Sci. 63, 9 (1993).

[10] M. Fried, T. Lohner, J. M. M. de Nigs, A. van Silfhout, L. J. Hanekamp, Z. Laczik, M. Q. Khanh, and J. Gyulai, J. Appl. Phys. 66, 5052 (1989).

[11] R. K. Sampson and H. Z. Massoud, J. Electrochem. Soc. 140, 2673 (1993).

[12] P. G. Snyder, M. C. Rost, G. H. Bu-Abbud, J. A. Woollam, and S. A. Alterovitz, J. Appl. Phys, 60, 3293 (1986).

[13] K. G. Merkel, P. G. Snyder, J. A. Woollam, S. A. Alterovitz, and A. K. Rai, Jpn. J. Appl. Phys. 28, 1118 (1989); J. A. Woollam, P. G. Snyder, K. G. Mcrkel, and S. A. Alterovitz, Materials Sei. Engl. B5, 291 (1990).

[14] D. E. Aspnes, W. E. Quinn, and S. Gregory, Appl. Phys. Lett. 56, 2569 (1969).

\subsection{References}

[1] O. Acher, E. Bigan, and B. Drevillon, Improvements of phase-modulated ellipsometry, Rev. Sci. Instrum. 60, 65 (1989).

[2] R. M. A. Azzam and N. M. Bashara, Ellipsometry and Polarized Light, North-Holland, Ncw York (1989).

\section{General}

D. E. Aspnes, The characterization of materials by spcetroscopic ellipsometry, in Spectroscopic Characterization Techniques for Semiconductor Technology, Proceedings SPIE Vol. 452, F. H. Pollak and R. S. Bauer, eds., SPIE, Bellingham, Washington (1983) pp. 60-70.

D. E. Aspnes, The aceurate determination of optical propertics by ellipsometry, in Handbook of Optical Constants of Solids, E. D. Palik, ed., Academic Press, Orlando, Florida (1985) pp. 89-112.

D. E. Aspnes, Analysis of semiconductor matcrials and structures by spectroellipsometry, in Spetroscopic Charactcrization Techniques for Semiconductor Technology III, Proccedings SPIE Vol. 946, O. J. Glembocki, F. H. Pollak, and F. Poncc, cds., SPIE, Bellingham, Washington (1988) pp. 84-97.

R. W. Collins, Automatic rotating element ellipsomcters: ealibration, operation, and real-time applications, Rev. Sci. Instrum. 61, 2029-2062 (1990).

J. F. Marchiando, Semiconductor Measurement Technology: A Software Program for Aiding the Analysis of Ellipsometric
Mcasurements, Simple Spectroscopic Models, Natt. Inst. Stand. Technol. Spceial Publication 400-84, U.S. Government Printing Office, Washington, DC (1990).

B. A. Tirri, A. Turncr, and P. C. Van Buskirk, Spectrocllipso. metric charactcrization of inhomogeneous films, in Modern $O_{p}$. tieal Charactcrization Techniques for Semiconductors and Semiconductor Devices, Procectlings SPIE Vol. 794, O. II. Glembocki, F. H. Pollak and J. J. Soong, cds., SPIE, Bcllingham, Washington (1987) pp. 252-261.

\section{Applications}

D. E. Aspnes and A. A. Studna, Optical detection and minimiza. tion of surface overlayers on semiconductors using spectroscopic cllipsometry, in Optical Characterization Techuiques for Scmiconductor Technology, Procecdings SPIE Vol. 276, D. E. Aspnes, S. So, and R. F. Potter, eds., SPIE, Bcllingham, Waslongton (1981) pp. 227-232.

D. E. Aspncs, J. P. Harlison, A. A. Studni, L. T. Furez, and M. K. Kelly, In situ optical measurements of the grow th of GaAs and $A \mid G a A s$ hy molecular beam epitaxy, in Spectroseopic Char. acterization Techniques for Scmiconductor Teclonology III, Pro. ecedings SPIE Vol. 946, O. J. Glembecki, F. II. Pollak, and F: Ponce, cds., SPIE, Bellingham, Washington (1988) pp. 112-121.

R. W. Collins and J. M. Cavese, In sim cllipwometry characterization of the growth of thin filn amorplous semiconductors, in Modern Optical Charactcrization Techniques for Semiconduc. tors and Semieonductor Devices, Proceedings SPIE Vol. 794, 0. H. Glembocki, F. 1\}. Pollak, and J. J. Soong, cok., Sl'll: lkellingham, Washington (1987) pp. 242-251.

Y. Demay, D. Arnoult, J. P. Gailliard, and P. Meclina, In sim spectroscopic cllipsometry Juring molecular-beam epitaxy of caunium mercury telluride, J. Vac. Sci. Technol. AS, 3139 (1987).

M. G. Doss, D. Chandler-IIorowitz, J. F. Marchiando, S. Krause, and $S$. Scraphin, Analysis for the claracterization of oxygen implanted silicon (SIMOX) by speetroncopic cllipwometry, Matcrials Rescarch Socicty Symposia Procecdings Vol. 2(r), Matcrials Research Society, Pittshurgl, Pennsylvania (1991) pp. 493-498.

B. Drevillon, It situ analysis of the groutlu of semiconductor ma tcrials by phase modulated cllipometry from UV toIR, in Sur. face and Interfice Anslysis of Microclectronic Matorials Processing and Growth, Procecolings SIIE Vol. 1186, L. J. Brill. son aud F. If. Pollak, cds, SPIE, Bellingham, Wavhington ( $\left.1 \mathrm{gk}^{\circ}\right)$ pp. $110-121$.

P. Dutti, G. A. Candela, D. Chandler.Ilorewitz, and J. F. Marchiando, Nondestructive characterization of oxyen planted silicon-on-insulator using multiple-angle cllipumctry, J. Appl. Plyss. 64, 2754-2756 (1988).

K. G. Mcrkel, P. G. Snyder, J. A. Woxllam, and S. A. Alterenitz. GiAs/AlGaAs superlatticc characterization by vatiatle angle spectroscopic ellipsometry, in Spectrosopic Chatacterization Tcclunigues for Semiconductor Technolngy III, Prucecting SPIE Vol. 946, O. J. Glcmlocki, F. II. Pollah. and F. l'onec. cds., SPIE, Bcllinghim, Washington (19k8) pp. 105-111. 
P. G. Snyder, J. A. Woollam, and S. A. Alterovitz, Variable angle of incidence speciroscopic ellipsomelric study of semiconduclor multilayer slructures, in Materials Characterizalion, Malerials Research Sociely Symposia Proceedings Vol. 69, N. Cheung and M.-A. Nicolcl, eds., Malcrials Rescarch Socicty, Pillsburgh, Pennsylvania (1986) pp. 245-250.

P. G. Snyder, K. G. Merkcl, and J. A. Woollam, Optical measuremenl of built-in and applied eleciric fields in AlGaAs/GaAs heterostructures, in Spcctroscopic Characlerizalion Techniques for Semiconduclor Technology III, Proceedings SPIE Vol. 946, O. J. Glembocki, F. H. Pollak, and F. Ponce, eds., SPIE, Bellingham, Washinglon (1988) pp. 98-104.

E. Taf1 and L. Cordes, Optical evidence for a silicon-silicon oxide inlerlayer, J. Elcclrochem. Soc. 126, 131-134 (1979).

J. A. Woollam and P. G. Snyder, Fundamentals and applications of variablc angle specıroscopic cllipsometry, Materials Sci. Eng. B5, 279-283 (1990).

\section{Infrared Spectroscopy}

\subsection{Introduction}

Infrared (IR) spectroscopy in the range from 10 $\mathrm{cm}^{-1}$ to $10,000 \mathrm{~cm}^{-1}$ can be used to determine impurity type and concentration in semiconductor materials, film thickness, semiconductor alloy composition, carrier density and scattering time. These determinations can be made for bulk, film, and microstructure systems. One application in Si measures the amount of interstitial oxygen, whose concentration is critical; correct values provide gettering action, reducing the level of other impurities, and hence, producing material with low leakage currents. Concentrations of oxygen in silicon and other impurities can be determined by infrared spectroscopic evaluation during processing.

\subsection{Physical Basis}

Infrared radiation interacts with semiconductor lattices, carriers, and impurities, and is affected by semiconductor layer thickness. Binary semiconductors like $\mathrm{GaAs}$ have vibrational lattice transverse optical (TO) modes which couple to infrared radiation, with resonant absorption when the incoming frequency matches the TO frequency. Ternary alloys like $\mathrm{Al}_{x} \mathrm{Ga}_{1-x}$ As display two TO modes, whose strength and frequency vary with $x$.

Semiconductor impurities can absorb infrared energy by photoionization of their bound carriers, or may modify their immediate lattice environment to produce a so-called local vibrational mode (LVM). In the case of photoionization, the impurity must be in a populated or ground state; hence, this absorption process is normally observed at cryo- genic temperatures. Local vibrational modes occur when an impurity atom is lighter than the host lattice. Impurities important to semiconductor processing such as oxygen and carbon in Si produce LVM absorptions in the infrared region. If a semiconductor film is not too highly absorbing (device grade material is often highly conductive, and, therefore, absorbing), interference between infrared radiation reflected from the front surface, and that reflected from the back, can produce fringes whose spacing is related to the film thickness. Finally, free charge carriers in a semiconductor also absorb electromagnetic radiation. The absorption increases with wavelength; hence, absorption can be significant at infrared wavelengths even for low carrier concentrations.

An important feature of optical processes such as those occurring in the IR region is that quantitative measurements can be made based on absorption, reflection, or transmission data, and then accurately described by simple theory. The infrared properties are specified by the complex dielectric function $\epsilon(\omega)=\epsilon_{1}(\omega)+i \epsilon_{2}(\omega)$, which is related to the complex refractive index $\bar{n}(\omega)=n(\omega)+i k(\omega)$ by

$$
\begin{gathered}
n^{2}-k^{2}=\epsilon_{1}(\omega) \\
2 n k=\epsilon_{2}(\omega) .
\end{gathered}
$$

If $\tilde{n}(\omega)$ is known, then the reflection and transmission properties can be calculated. For instance, a semiconductor film has at normal incidence a frontsurface reflection coefficient $R$,

$$
R=\frac{\left[(n-1)^{2}+k^{2}\right]}{\left[(n+1)^{2}+k^{2}\right]}
$$

and a transmission coefficient,

$$
T=\frac{(1-R)^{2} \mathrm{e}^{-\alpha d}}{\left(1-R^{2} \mathrm{e}^{-2 \alpha d}\right)}
$$

where $\alpha$ is the absorption coefficient $(=4 \pi k / \lambda)$ and $d$ is the film thickness. These expressions apply only when interference effects can be neglected, i.e., when noncoherent light is used.

For absorption due to lattice vibrations, or due to local impurity vibrational modes, the dielectric function $\epsilon$ is

$$
\epsilon(\omega)=\epsilon_{x}+\frac{S \omega_{\mathrm{R}}^{2}}{\omega_{\mathrm{R}}^{2}-\omega^{2}-i \omega \Gamma} .
$$


In this well-known Lorentzian form, $\epsilon_{x}$ is the high-frequency limit of $\epsilon(\omega) ; S$ is the oscillator strength; $\Gamma$ is a damping term; and the resonant frequency $\omega_{\mathrm{R}}$ is the TO frequency for a lattice oscillation, or characteristic fingerprint frequency for an impurity vibrational mode. For a ternary semiconductor like $\mathrm{Al}_{1_{-x}} \mathrm{Ga}_{x} \mathrm{As}$, each TO mode is represented by a resonant term like that in Eq. (7), whose parameters depend on $x$.

If there are free carriers present, $\epsilon$ has an additional term $-\epsilon_{\infty} \omega_{p}^{2} /[\omega(\omega-i / \tau)]$, where $\tau$ is the carrier scattering time, and $\omega_{\mathrm{p}}{ }^{2}$ is the plasma frequency $4 \pi \mathrm{Ne}^{2} / m^{*} \epsilon_{\infty}$, with $N$ the carrier concentration and $m^{*}$ the carrier effective mass. Hence, $N$ and the drift mobility $\mu=e \tau / m^{*}$ can be found from these parameters if $m^{*}$ is known. Also, the dc resistivity $\rho=m^{*} / n e^{2} \tau=\omega_{p}{ }^{2} \tau$ can be found from these quantities, even if $m^{*}$ is not known.

From the theory discussed above, measured reflection, transmission, and absorption data can be related to the microscopic semiconductor parameters. Thus, concentrations of impurity oxygen and carbon in silicon, for instance, in the parts-per-million range can be determined. Infrared analysis can also be used to determine carrier concentrations, mobilities, and resistivities for carrier concentrations as low as $10^{14} \mathrm{~cm}^{-3}$, with results that agree well with conventional Hall effect and resistivity data.

Further, analysis of infrared reflectivity for thin films of semiconductors, which show interference effects, can be used to accurately determine the thicknesses of films in the micrometer range. For nonabsorbing films, the peaks of observed interference fringes occur at the wavelengths

$$
\lambda_{\mathrm{P}}=\frac{2 n(\omega) d}{p}
$$

where $d$ is the layer thickness, $n(\omega)$ is the real part of the refractive index, and $p$ is the interference order, an integer or half integer $1 / 2,1,3 / 2 \ldots n(\omega)$ is known for semiconductors of interest, so that $d$ can be derived from Eq. (8).

Infrared methods can also be used to determine the presence of shallow impurities. A shallow donor impurity behaves like a hydrogen atom immersed in a medium with dielectric constant $\epsilon$ and conduction band effective mass ratio $m^{*} / m_{0}$, where $m_{0}$ is the free electron mass. From the Bohr model, the ionization energy (in eV) is

$$
E_{\text {ion }}=\frac{13.6}{\epsilon^{2}}\left(\frac{m^{*}}{m_{0}}\right)
$$

which is approximately $6 \mathrm{meV}$ for GaAs. This simple model cannot predict ionization energies for different impurities in different materials, but shows that shallow donor ionization energies lie in the infrared region. Their exact values, and hence identification of the particular impurity, can be found from infrared photoconductivity spectra.

The theory developed above can be used to anlalyze inhomogeneous microstructures composed of layers of different semiconductors. Each layer is described by the same infrared theory and parameters that define its bulk behavior, to give its complex refractive index. Then, using standard theory for the reflection and transmission at each interface, the total infrared response of the structure can be calculated by computer. This model works well in fitting such data to determine average carrier properties, layer thicknesses, and phonon behavior which is related to microstructure properties and quality.

\subsection{Experimental and Technical Details}

Infrared spectroscopy often requires only minimal sample preparation, and the low energy and power of infrarcd radiation sources guarantec that the samples are not altered by the measurement. Because infrared light typically penctrates several micrometers into a seniconductor, this radiation can also be used to examine the various layered regions of an entire microstructure such as a superlattice.

Low source intensity and low detector sensitivity in the infrared region make Fourier transform spectroscopy the method of choice for obtaining IlR spectra. In the Fourier method, infrared light, having traversed or been reflected from a sample, is an. alyzed with an interfcrometer. The optical intensity reaching the detector through the interferometer is the optical Fourier transform of the desired trans. mission or reflection spectrum. The interference spectrum is computationally transformed back into an intensity spectrum by means of the Fast Fourier transform algorithm on a computer. The light throughput advantage of a large interferometer apcrture rather than the narrow slit of a conven. tional dispersive monochromator is referred to as the Jacquinot advantage. In addition, the interferometer allows simultancous observation of many wavelengths, the so-callcd Fellgett advantage.

Figure 3 is a schematic diagram of a Michelson interferomcter. Radiation from a broad-band source, $s$, is divided by a bcamsplitter, BS. Light reflected from the beamsplitter is also reflected 
from fixed mirror M1, whereas light transmitted through the beamsplitter is reflected from a movable second mirror, M2. The two light beams recombine to produce a net intensity whose magnitude depends on the difference $\Delta$ between the paths that the two beams traverse. As mirror M2 moves, $\Delta$ varies continuously. The intensity function $I(\Delta)$, called the interferogram, is

$$
I(\Delta)=\int_{0}^{\infty} S(f)[1+\cos (2 \pi f \Delta)] \mathrm{d} f
$$

where $S(f)$ is the intensity spectrum of the source as modified by the sample, and $f=\omega / \pi c$ is the optical frequency in $\mathrm{cm}^{-1}$. Equation (10) is the cosine Fourier transform of $S(f)$, which can be calculated from the inverse transform

$$
S(f)=\int_{0}^{\infty}\left[I(\Delta)-\frac{1}{2} I(0)\right] \cos (2 \pi f \Delta) \mathrm{d} \Delta
$$

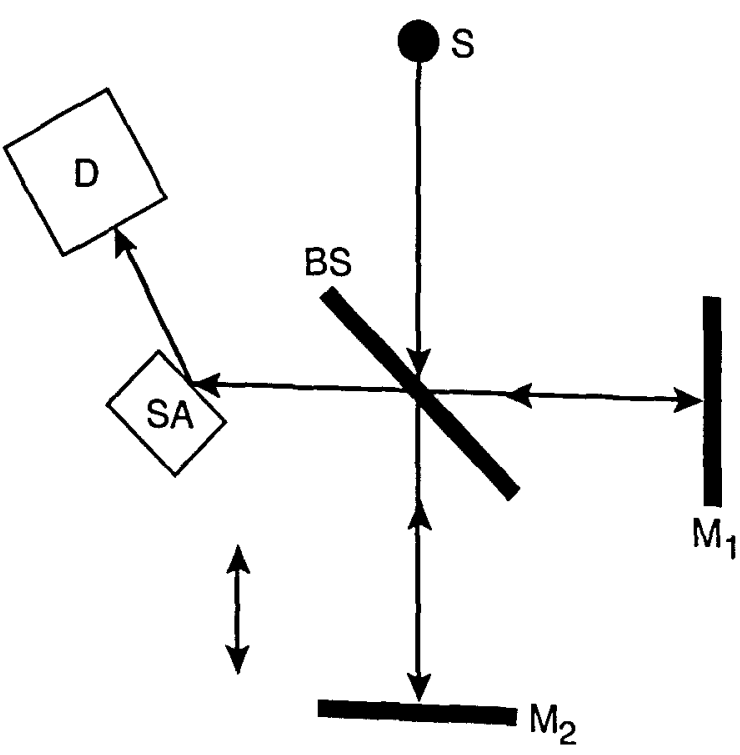

Fig. 3. Diagram of a Miehelson interferometer configured for sample reflectanee measurements. S, sourec; BS, beamsplitter; M1, fixed mirror; M2, movable mirror, which moves as indicated by the double-headed arrow; SA, sample; D, detector. The type of source and beamsplitter depends on the region of the infrared where data are to be obtained. The light beams reflected from $\mathrm{M} 1$ and $\mathrm{M} 2$ recombine to form the interferogram signal, which is measured by the detector.

This is implemented in the laboratory by processing the measured $I(\Delta)$ with a computer to carry out the inverse transform. The spectral resolution in wavenumbers of the Fourier system is $1 / L$, where $L$ is the total travel of the movable mirror. Most machines use a rapid scan method, where the mirror is swept through its entire travel in a short time. Many sweeps are averaged together to enhance the signalto-noise ratio.

Because of the small intensities of infrared sources, especially at the very long wavelengths of the far infrared spectrum, high-quality detectors are important. Liquid helium bolometers give the highest sensitivity, but are expensive and complex to operate. Mercury-cadmium-telluride detectors operating at liquid nitrogen temperatures work well in the mid infrared spectrum. Pyroelectric detectors operate at room temperature and are simple and rugged. They are sufficiently sensitive, from ultraviolet to millimeter wavelengths, for much semiconductor work.

Commercial Fourier transform infrared systems are available that cover the near infrared to the far infrared spectrum, by suitable choice of light source, beam splitter, and detector. To avoid the effect of water vapor absorption on the desired spectrum, these spectrometers are evacuated. Often, semiconductor samples must be cooled in order to better study electronic properties by removing the effects of lattice vibrations or phonons in the absorption spectra. This can be accomplished to $77 \mathrm{~K}$ with liquid nitrogen, and to $4.2 \mathrm{~K}$ with a liquid helium cryogenic system or by a mechanical refrigerator.

\subsection{Illustrative Applications}

Figure 4 illustrates the absorption peaks for interstitial oxygen at $1107 \mathrm{~cm}^{-1}$ and substitutional carbon at $605 \mathrm{~cm}^{-1}$ in Czochralski-grown silicon. Such absorption data can be converted into oxygen concentration values, giving a rapid, nondestructive way to determine this important quantity. Figure 5 demonstrates how a semiconductor film, in this case an epitaxial layer of high-resistivity silicon deposited on low-resistivity silicon, gives clear interference fringes that can be used to measure the layer thickness. Figure 6 correlates resistivity obtained from infrared measurements with resistivity obtained from carrier transport measurements. The data, from epitaxial $\mathrm{n}$ - and p-type $\mathrm{Hg}_{x} \mathrm{Cd}_{1-x} \mathrm{Te}$ films, are compared to results from conventional electrical measurements, which require ohmic contacts that can be difficult to apply. Figure 7 shows infrared reflectance data for an AlAs-GaAs superlattice. As the caption discusses in detail, the TO phonon mode for each constituent material is clear, as are interference fringes and other features. The simple theory for infrared phonon response gives a 


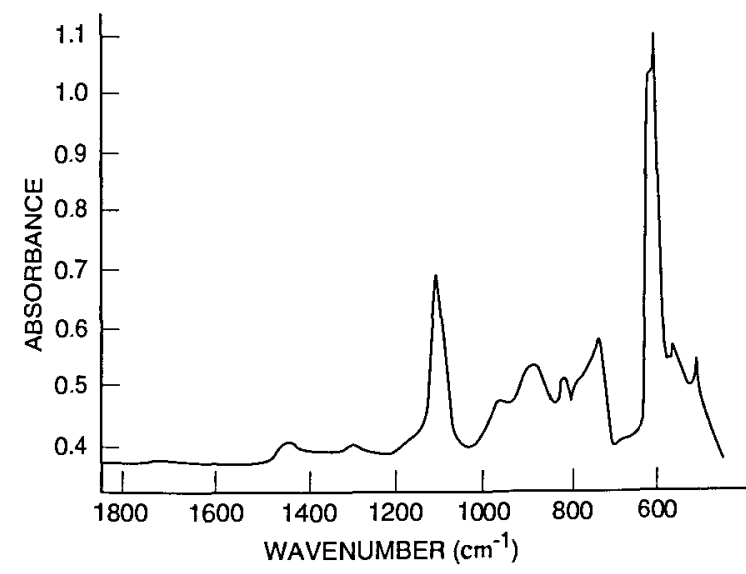

Fig. 4. Infrared absorbance for a Czochralski-grown silicon wafer $2 \mathrm{~mm}$ thick, derived from transmission spcctra using a commercial Fourier spectrometcr with a mcrcury-cadmiumtelluride detector. The characteristic interstitial oxygen line at $1107 \mathrm{~cm}^{-1}$ and the substitutional carbon line at $605 \mathrm{~cm}^{-1}$ appear. Much of the remaining structure is due to silicon phonon modes. The absorbance at $1107 \mathrm{~cm}^{-1}$ is lincarly related to the oxygen concentration. Calibration data exist to convert absorbance into oxygen concentration in parts per million atomic or atoms per cubic centimetcr. (See Sec. 3.5, Applications Rcfs., Krishnan, Stout, and Watanabe, in Practical Fourier Transform Infrared Spectroscopy, J. R. Ferraro and K. Krishnan, Eds., Academic Press, San Diego (1990), fig. 5, p. 298.)

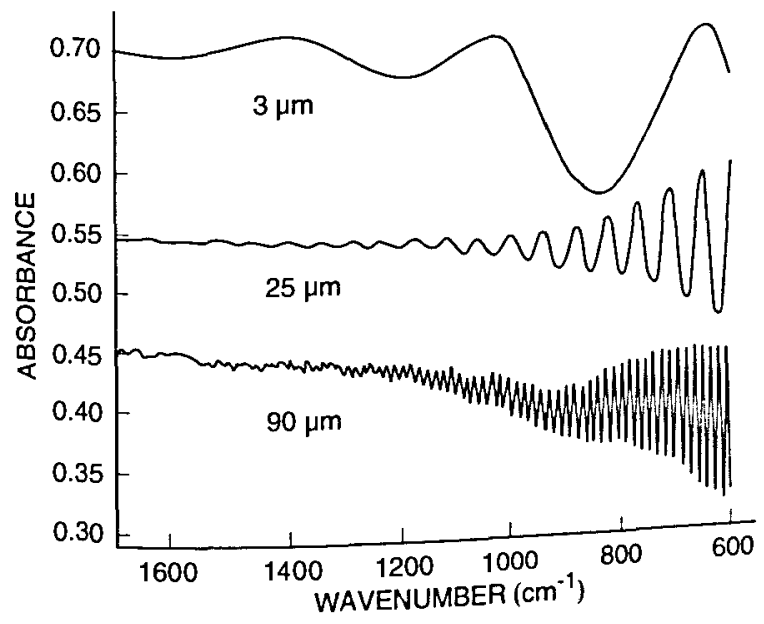

Fig. 5. Infrarcd reflcctance spcctra from structures consisting of low carrier concentration silicon epitaxial layers on high concentration silicon substrates, showing interference fringes that can be used to determine epitaxial layer thickness. Layers of different thickness produce different fringe spacings, according to Eq. (8). (See Sec. 3.5, Applications Refs., Krishnan, Stout, and Watanabe, in Practical Fourier Transform Infrared Spectroscopy, J. R. Fcrraro and K. Krishnan, Eds., Academic Press, San Diego (1990), fig. 25, p. 333.) fit which reproduces all the main features of the spectra, and allows an estimale of layer thickness.

Table 4 gives the sensitivities of typical quantities measured by infrared spectroscopy such as interslitial oxygen concentrations in $\mathrm{Si}$ and $\mathrm{GaAs}$, substilu. tional carbon concentrations in $\mathrm{Si}$ and $\mathrm{GaAs}$, and $B$, $\mathrm{P}$, and As concentrations in Si. For more specific details, the reader should refer to the citations given in the table.

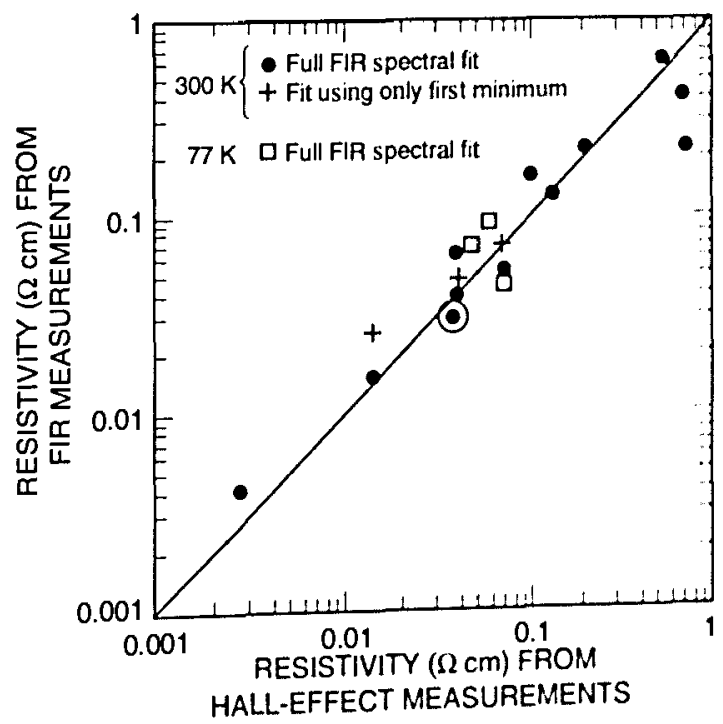

Fig. 6. Infrared values for de resistivity compared to tesistivity values from standard electrical (resistivity-l lall cffect) measure. ments, for several $n$ - and p-type Hg, ., Cd, Te films on CoTe suhstrates. The films were typically seteral micrometers thick withe values of 0.2 to 0.4 . Results at both $3(0) K$ and $77 K$ atc shown. Resistivity values marked "Full FIR spectral fil" werc derived from fits to the full far infrated (FIR) spectrum aner the range $20 \mathrm{~cm}^{-1}$ to $230 \mathrm{~cm}^{-1}$, using the theory developed in this section. Resistivity values marked "Fit using only first minimum" wetc derived from the measured position of one particular feature of the FIR spectra, the wo-called plasnon-phomon misimum whose location depends on resistivity. The wlid line represents perfort agrecment between the infrated and the conventional clectrical results. The contactless infrated method aresces well with the time-consuming ind destructive clectrical methes reciusting con. tacts. (See Sce 3.5, Applicitions Refs.. Janes. Buyd. Kintel. Pcrhowitz, and Braunstion (1956), fig. 2, p. 2057.)

\subsection{References}

\section{General}

R. J. Bell. Introductury Fouricr Transform Spectrmong. Aca denic Press, New York (1972).

G. L. Carr, S. Perkemitz, and D. B. Tanner. Fat infratcd proper ties of inhonogenenus matcrials, in Infrated and Milimeter

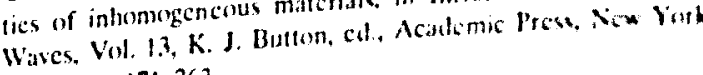
(19s5) pp. 171-263. 
E. D. Palik and R. T. Holm, Optical characterization of semiconductors, in Nondestructive Evaluation of Semiconductor Materials and Devices, J. N. Zemel, ed., Plenum, Ncw York (1979) pp. 315-345.

S. Perkowitz, Submillimeter solid state physies, in Infrared and Millimeter Waves, Vol. 8, K. J. Button, ed., Academic Press, New York (I983) pp. 71-125.
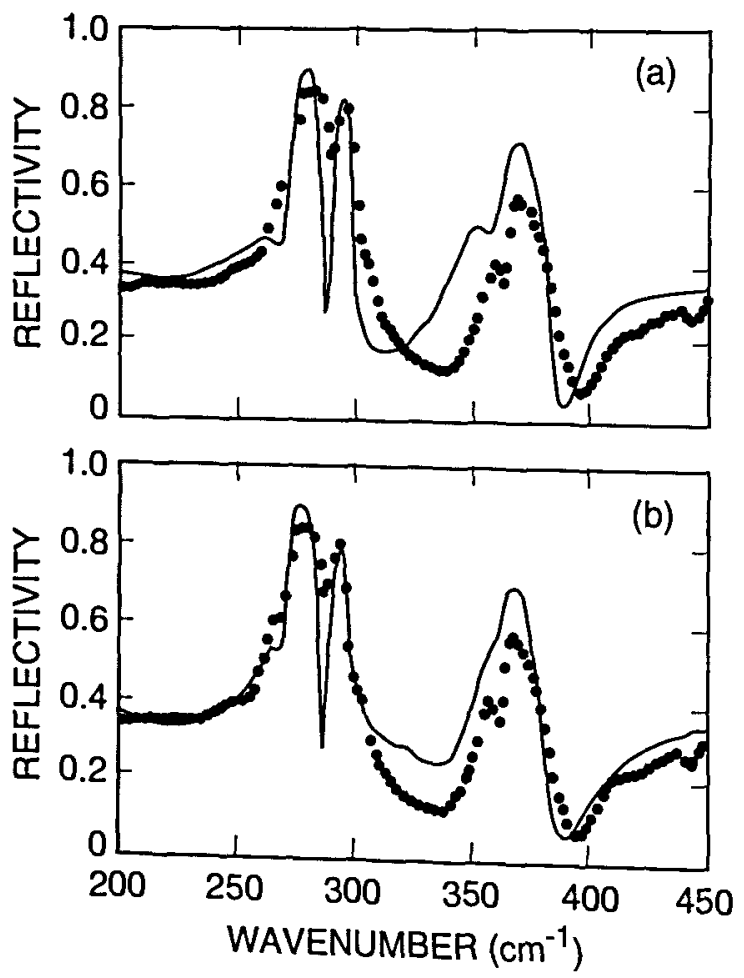

Fig. 7. Infrared reflectivity spectra for an AlAs-GaAs superlattice with 50 layer pairs. Panels (a) and (b) show the same data points. The peaks at $275 \mathrm{~cm}^{-1}$ and $365 \mathrm{~cm}^{-1}$ are the GaAs TO mode and AlAs TO mode, respectively. The peak at $290 \mathrm{~cm}^{-1}$ and shoulder at $355 \mathrm{~cm}^{-1}$ are interference fringes. The minima in the spectra lie at the positions of the structure's longitudinal optical phonon modes, which are sensitive to layer thickness. In Panel (a), the fitted solid line uses known phonon parameters for GaAs and AlAs, and the grower's nominal layer thickness $d_{\text {NAs }}=d_{\text {GaAs }}=10 \mathrm{~nm}$. The improved fit in Panel (b) uses the same phonon parameters, but allowed each layer thickness to vary for the best result. The numbers reported by Sudharsanan et al. gave $d_{\text {NAs }}=(7.5 \pm 0.2) \mathrm{nm}$ and $d_{\text {GaAs }}=(8.2 \pm 0.2) \mathrm{nm}$, in agreement with the $x$-ray results $d_{\mathrm{AlA}}=(8.3 \pm 0.8) \mathrm{nm}$ and $d_{\mathrm{CeAs}}=(8.3 \pm 0.8) \mathrm{nm}$. (See Sec. 3.5, Applieations Refs., Sudharsanan, Perkowitz, Lou, Drummond, and Doyle (1988),
fig. I, p. 658.)

\section{Applications}

P. M. Amirtharaj, G. Holah, and S. Perkowitz, Far infrared spec troscopic study of $\mathrm{In}_{1-x} \mathrm{Ga}_{x} A s_{y} \mathrm{P}_{1-y}$, Phys. Rev. B 21, 5656-5661
(I980).
G. J. Brown and W. C. Mitchel, Mid-infrared spectral response of semi-insulating GaAs, in Impurities, Defects and Diffusion in Semiconductors: Bulk and Layered Structures, Materials Research Society Symposia Proceedings Vol. 163, D. J. Wolford, J. Bernholc, and E. E. Haller, eds., Materials Research Society, Pittsburgh, Pennsylvania (1989) pp. I57-162.

J. P. Fillard, M. Castagne, J. Bonnafe, and J. Gall, Scattering and absorption of infrared light on EL2 clusters in GaAs semi-insulating matcrials, in Matcrials Characterization, Materials Research Society Symposia Proceedings Vol. 69, N. Cheung and M.-A. Nicolet, eds., Matcrials Rescarch Socicty, Pittsburgh, Pennsylvania (1986) pp. 231-236.

D. K. Gaskill, J. Davis, R. S. Sillmon, and M. N. Sydor, Nondestructive characterization of carricr concentration and thickness uniformity for semiconductors using infrared reflectance spectroscopy, in Modern Optical Characterization Techniques for Semiconductors and Scmiconductor Devices, Proceedings SPIE Vol. 794, O. H. Glembocki, F. H. Pollak, and J. J. Soong, eds., SPIE, Bcllingham, Washington (1987) pp. 231-241.

J. Gcist, Infrared absorption cross section of arsenic in silicon in the impurity band region of concentration, Appl. Optics 28 , 1193-1199 (1988).

C. E. Jones, T. N. Casselman, J. P. Fauric, S. Perkowitz, and J. Schulman, Infrared propertics and bandgaps of $\mathrm{HgTc} / \mathrm{CdTe}$ superlattices, Appl. Phys. Lett. 47, 140-142 (1985).

C. E. Joncs, M. E. Boyd, W. H. Konkel, S. Pcrkowitz, and R. Braunstein, Noncontact clectrical characterization of epitaxial HgCdTe, J. Vac. Sci. Technol. A4, 2056-2060 (1986).

K. Krishnan, Precise and Rapid Measurement of Interstitial Oxygen Concentration in Silieon, Bio-Rad Semiconductor Notes No. 102, Bio-Rad Semiconductor Measurement Systems, 237 Putnam Avc., Cambridge, MA 02139, April 1983.

K. Krishnan, A study of the spatial distribution of the oxygen content in silicon wafers using an infrared transmission microscope, Bio-Rad Semiconductor Notes No. 105, Bio-Rad Scmiconductor Measurement Systems, 237 Putnam Ave., Cambridge, MA 02139, January 1985.

K. Krishnan and R. B. Mundhe, Characterization of semiconducting silicon using FT-IR spectroscopy, in Spectroscopic Characterization Techniques for Semiconductor Technology, Proccedings SPIE Vol. 452, F. H. Pollak and R. S. Baucr, cds., SPIE, Bellingham, Washington (1983) pp. 71-78.

K. Krishnan, P. J. Stout, and M. Watanabe, Characterization of semiconduetor silicon using Fourier transform infrared spectrometry, in Practieal Fourier Transform Infrared Spectroscopy, J. R. Ferraro and K. Krishnan, eds., Academic Press, San Diego (1990) pp. 285-349.

B. Lou, S. Perkowitz, and R. Sudharsanan, Anisotropy and infrared response of the AIAs-GaAs superlattice, Phys. Rev. B 38, 2212-2214 (1988). [Erratum: Phys. Rev. B 39, 1387 (1989)]

E. Mcrk, J. Heyman, and E. E. Haller, Infrared absorption study of zinc-doped silicon, in Impurities, Defects and Diffusion in Semiconductors: Bulk and Layered Structures, Volume 163, Materials Research Society Sym posia Procecdings, D. J. Wolford, J. Bernholc, and E. E. Haller, cds., Materials Research Society, Pittsburgh, Pennsylvania (1989) pp. 15-20. 
W. J. Moore, Infrared transmission charactcrization of p-type gallium arsenide, in Optical Characterization Techniques for Semiconductor Technology, Procecdings SPIE Vol. 276, D. E. Aspnes, S. So, and R. F. Potter, eds., SPIE, Bellingham, Washington (1981) pp. 101-103.

R. C. Newman, Localized vibrational mode spectroscopy of impurities in semiconductor crystals, in Growth and Charactcrization of Semiconductors, R.A. Stradling and P.C. Klipstein, eds., Adam Hitger, Bristol (1990) pp. 105-118.

S. Perkowitz and J. Breecher, Characterization of GaAs by far infrared reflectivity, Infrared Phys. 13, 321-326 (1973).

S. Perkowitz, Far infrared characterization of $\mathrm{Hg}_{x} \mathrm{Cd}_{1-x} \mathrm{Te}$ and related etectronic materials, J. Electronic Materials 14, 551-562 (1985).

S. Perkowitz, D. Rajavel, I. K. Sou, J. Reno, J. P. Faurie, C. E. Jones, T. Casselman, K. A. Harris, J. W. Cook, and J. F. Schctzina, Far infrared study of alloying in $\mathrm{HgTe}$-CdTe supcrlattices, Appl. Phys. Lett. 49, 806-809 (1986).

S. Perkowitz, Far infrared spectroscopy of $\mathrm{Hg}_{x} \mathrm{Cd}_{1-x} \mathrm{Tc}$ and rclated materiats, in Far-Infrared Science and Tcchnology, Proceedings SPIE Vol. 666, J. R. Izatt, cd., SPIE, Bellingham, Washington (1986) pp. 120-125.

S. Perkowitz, R. Sudharsanan, and S. S. Yom, Far infrarcd analysis of alloy structure in HgTe-CdTe supcrlattices, J. Vac. Sci. Technot. A5, 3157-3160 (1987).

S. Perkowitz, R. Sudharsanan, S. S. Yom, and T. J. Drummond, AlAs phonon parameters and heterostructure characterization, Solid State Commun. 62, 645-647 (1987).

B. Senitzky and S. P. Weeks, Infrared reflcctance spectra of thinepitaxiat silicon tayers, in Optical Characterization Techniques for Semiconductor Technology, Proccedings SPIE Vol. 276, D. E. Aspnes, S. So, and R. F. Potter, eds., SPIE, Bellingham, Washington (1981) pp. 222-226.

R. Sudharsanan, S. Perkowitz, S. S. Yom, and T. J. Drummond, Far infrared reflectance spectroscopy of AlAs-GaAs microstructures, in Modcrn Optical Charactcrization Tcchniqucs for Semiconductors and Semiconductor Devices, Procecdings SPIE Vol. 794, O. H. Glembocki, F. H. Pollak, and J. J. Soong, eds., SPIE, Betlingham, Washington (1987) pp. 197-20t.

R. Sudharsanan, S. Perkowitz, B. Lou, T. J. Drummond, and B. L. Doyle, Far-infrared charactcrization of AlAs-GaAs superlattice structure, Supcrlattices and Microstructures 4, 657-660 (1988).

L. E. Taroff, C. J. Mincr, and A. J. Springthorpc, Epitaxial layer thickness measurements by reflcction spcctroscopy, J. Elcctronic Materials 18, 361-367 (1989).

W. M. Theis, C. W. Litton, and K. K. Bajaj, Infrarcd localized mode spectroscopy of carbon-implanted GaAs, in Optical Characterization Techniques for Scmiconductor Technology, Procecdings SPIE Vol. 276, D. E. Aspnes, S. So, and R. F. Potter, ed., SPIE, Bellingham, Washington (1981) pp. t09-1t2.

J. Vindevoghel, M. Vindevoghcl, and Y. Leroy, Mtillimetric and far infrared conductivity for $\mathrm{p}$-Si. Evidence for interband transitions, Infrared Phys. 18, 99-105 (1978).
J. M. Zavada, H. A. Jenkinson, and T. J. Gavanis, Oplical propcrtics of proton implanted n-type GaAs, in Optical Characterization Techniques for Scmiconductor Technology. Prucecdings SPIE Vol. 276, D. E. Aspnes, S. So, and R. F. Potter, eds., Sttt: Bcllingham, Washington (1981) pp. 104-108.

\section{Optical Microscopy}

\subsection{Introduction}

In applications where the dimensions of interest are below the optical diffraction linit $(\sim 0.8 \mu \mathrm{m})$, electron microscopy is used by necessity. However, traditional optical methods remain useful for a large number of applications such as examining topological features larger than $-1.0 \mu \mathrm{m}$, cx:tmining defects, or counting etchpits. Several speciatlized forms of optical microscopy are highly vatuable: Nomarski, scanning litser, and microspectrophotometry. In Nomarski microscopy, interference methods are used to increase the contrast between smitl differences in the surfitce level of a semiconductor wafer. Scanning microscopy in both the visible and infrared spectral ranges allows two-dincussional imaging of features in a latyer or structure. linatly, microspectrophotometry allows film thickness determination from spectrit anatysis of reflected light.

Scanning microscopy is atso used in bott the visible and the infrared spectral ranges to form twodimensional images of inhomogeneities in a semiconductor. The form eatled confocil microscopy produces three-dimensional imitges [1]. One visible light-scitnning teclenique of special interest is the optical-beam-induced eurrent method (abbreviated $O B I C$, or sometimes $L . I 3 I C$, for laser-heaminduced current), which detects grain boundaries, dislocations, and other defects in semiconductors and semiconductor devices. OlBIC images represent spatial distributions of electrically active defects that include inclusions, strain, damage, precipitites, stacking faults, twin boundaries, dislocittion clusters, and bandgap and doping variations. In this technique, a focused laser beam is scanned across the surface of the sample, and the induced current between two remote contats on the sample is mca. sured as a function of the laser beam position. The induced current is a result of the charge-separation effect of the regions in the vicinity of the light. light incident on the area of the sample which is homoge neous and defect-free dnes not generate any induced current. Infrared seanning has becn used to study individual precipitate particles in Si ingots. and to examine GaAs and other materials. 
Table 4. Infrared sensitivity. Given are sensitivities for the measurement of interstitial oxygen [ $\mathrm{O}_{\mathrm{i}}$ ], substitutional carbon [ $\mathrm{C}_{\mathrm{s}}$ ], and nitrogen [Si-N-Si], in crystalline $\mathrm{Si}$ and substitutional carbon $\left[\mathrm{C}_{\mathrm{G}}\right]$ and interstitial oxygen $\left[\mathrm{O}_{\mathrm{i}}\right]$ in crystalline GaAs. Also given are sensitivities for measurement of compositions, $x$, of $\mathrm{Al}_{x} \mathrm{Ga}_{1-x} \mathrm{As}$ and $\mathrm{Hg}_{r} \mathrm{Cd}_{1-x} \mathrm{Te}$ and for carrier concentrations, $N_{\mathrm{d}}$, in $\mathrm{Si}$ and $\mathrm{GaAs}$. The sensitivity of far infrared low-temperature absorption measurements for substitutional boron $\left[B_{\mathrm{s}}\right]$; phosphorus $\left[\mathrm{P}_{\mathrm{s}}\right]$; and arsenic $\left[A s_{\mathrm{s}}\right]$ are also given. The notations used for the measured quantity column are absorption eoeffieients, $\alpha$, at subscripted wavelength in $\mathrm{cm}^{-1}$, $\mathrm{c} \mathrm{g}$, $\alpha_{1167}$; absorption coefficient full width product, $\alpha \Delta$, at subscripted wavelength, c.g., $\alpha \Delta_{845}$; LO phonon frequency, wLo; plasma resonance frequency, ap; transmission, $T$; and frequency, $\omega$

\begin{tabular}{|c|c|c|c|c|c|c|}
\hline Method & Matrix & Quantity & $\begin{array}{l}\text { Measured } \\
\text { quantity }\end{array}$ & Conversion & Sensitivity" & $\begin{array}{l}\text { Ref. } \\
\text { see below) }\end{array}$ \\
\hline LVM & $\mathrm{Si}$ & {$\left[\mathrm{O}_{\mathrm{i}}\right]$} & $\begin{array}{c}\alpha_{1107} \\
@ 300 \mathrm{~K}\end{array}$ & {$\left[O_{i}\right]=\alpha \times 3.03 \pm 0.02 \times 10^{17} \mathrm{~cm}^{-2}$} & $\pm 2 \times 10^{15} \mathrm{~cm}^{-3}$ & 1 \\
\hline LVM & $\mathrm{Si}$ & {$\left[\mathrm{O}_{\mathrm{i}}\right]$} & $\begin{array}{c}\alpha_{1107} \\
@ 300 \mathrm{~K}\end{array}$ & {$\left[\mathrm{O}_{\mathrm{i}}\right]=\alpha \times 3.14 \times 10^{17} \mathrm{~cm}^{-2}$} & $\pm 2 \times 10^{15} \mathrm{~cm}^{-3}$ & 2 \\
\hline LVM & Si & {$\left[\mathrm{C}_{\mathrm{s}}\right]$} & $\begin{array}{c}\alpha_{\text {kx }} \\
@ 300 \mathrm{~K}\end{array}$ & {$\left[C_{s}\right]=\alpha \times 1.1 \times 10^{17} \mathrm{~cm}^{-2}$} & $\pm 2 \times 10^{16} \mathrm{~cm}^{-3}$ & 3 \\
\hline Absorption & Si & [Si-N-Si] & $\begin{array}{c}\alpha_{963} \\
@ 300 \mathrm{~K}\end{array}$ & {$\left[\mathrm{~N}_{\mathrm{s}}\right]=\alpha \times 1.3 \times 10^{17} \mathrm{~cm}^{-2}$} & $\pm 2 \times 10^{15} \mathrm{~cm}^{-3}$ & 4 \\
\hline LVM & GaAs & {$\left[\mathrm{C}_{\mathrm{C}_{a}}\right]$} & $\begin{array}{l}\alpha \Delta_{583} \\
@ 77 \mathrm{~K}\end{array}$ & $\begin{array}{c}{\left[\mathrm{C}_{\mathrm{s}}\right]=\alpha \Delta \times 1.1 \times 10^{16} \mathrm{~cm}^{-1}} \\
{\left[\mathrm{C}_{\mathrm{s}}\right]=\alpha \Delta \times 8 \pm 2 \times 10^{15} \mathrm{~cm}^{-1}}\end{array}$ & $\pm 2 \times 10^{14} \mathrm{~cm}^{-3}$ & $\begin{array}{l}5 \\
6\end{array}$ \\
\hline LVM & GaAs & {$\left[\mathrm{O}_{\mathrm{i}}\right]$} & $\begin{array}{c}\alpha \Delta_{845} \\
@ 10 \mathrm{~K}\end{array}$ & {$\left[C_{s}\right]=\alpha \Delta \times 8 \times 10^{16} \mathrm{~cm}^{-1}$} & $\pm 2 \times 10^{15} \mathrm{~cm}^{-3}$ & 7 \\
\hline $\begin{array}{l}\text { Phonon } \\
\text { frequency }\end{array}$ & $\mathrm{Al}_{x} \mathrm{Ga}_{1-x} \mathrm{As}$ & $x$ & $\begin{array}{l}\omega_{\text {Lo }} \text { or } \omega_{\text {To }} \\
@ 300 \mathrm{~K}\end{array}$ & $\begin{array}{c}\left(\omega_{\mathrm{LO}} / 2 \pi c\right) / \mathrm{cm}^{-1}= \\
292.4+70.8 x-26.8 x^{2}-41.13 x^{3}\end{array}$ & & 8 \\
\hline IR cut off & $\mathrm{Hg}_{\mathrm{x}} \mathrm{Cd}_{1-x} \mathrm{Tc}$ & $x$ & $T$ vs $\omega$ & Ref. 9 & & 9 \\
\hline $\begin{array}{l}\text { IR plasma } \\
\text { frequency }\end{array}$ & $\mathrm{Si}$ & $N_{\mathrm{d}}$ & $\begin{array}{c}\omega_{\mathrm{p}} \\
@ 300 \mathrm{~K}\end{array}$ & $\omega_{\mathrm{p}}^{2}=4 \pi N_{\mathrm{c}} e^{2} / \mathrm{\epsilon m} *$ & & 10 \\
\hline $\begin{array}{l}\text { 1R plasma } \\
\text { frequency }\end{array}$ & GaAs & $N_{\mathrm{d}}$ & $\stackrel{\omega_{\mathrm{p}}}{@ 300 \mathrm{~K}}$ & $\omega_{p}^{2}=4 \pi N_{c} e^{2} / \epsilon m^{*}$ & & 11 \\
\hline Absorption & $\mathrm{Si}$ & {$[\mathrm{B}]$,} & $\begin{array}{l}\alpha \Delta_{320} \\
@ 12 \mathrm{~K}\end{array}$ & {$\left[\mathrm{~B}_{\mathrm{s}}\right]=\alpha \times 1.1 \times 10^{17} \mathrm{~cm}^{-2}$} & $\pm 1.5 \times 10^{12} \mathrm{~cm}^{-3}$ & 12 \\
\hline Absorption & Si & {$\left[P_{s}\right]$} & $\begin{array}{l}\alpha \Delta_{31 k} \\
@ 12 \mathrm{~K}\end{array}$ & {$\left[P_{\mathrm{s}}\right]=\alpha \times 1.1 \times 10^{17} \mathrm{~cm}^{-2}$} & $\pm 1.5 \times 10^{12} \mathrm{~cm}^{-3}$ & 12 \\
\hline Absorption & $\mathrm{Si}$ & {$\left[A s_{s}\right]$} & $\begin{array}{l}\alpha \Delta_{3 \times 2} \\
@ 12 \mathrm{~K}\end{array}$ & {$\left[A s_{s}\right]=\alpha \times 1.1 \times 10^{17} \mathrm{~cm}^{-2}$} & $\pm 1.5 \times 10^{12} \mathrm{~cm}^{-3}$ & 12 \\
\hline
\end{tabular}

\footnotetext{
" Calculated as the concentration-equivalent-of-noisc assuming $\pm 0.1 \%$ noise in transmission.
}

References

[1] T. Iizuka, S. Takasu, M. Tajima, T. Arai, T. Nozaki, N. Inoue, and M. Watanabe, J. Electrochem. Soc. 132, 1707 (1985).

[2] A. Baghdadi, W. M. Bullis, M. C. Croarkin, Yue-Zhen Li, R. I. Scace, R. W. Series, P. Stallhofer, and M. Watanabe, J. Eleetrochem. Soc. 136, 2015 (1989); ASTM Standard F1188, Annual Book of ASTM Standards, 10.05 (ASTM, Philadelphia, PA
(1991).

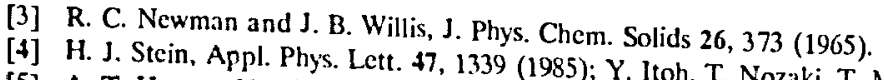

[5] A. T. Hunter, H. Kimura, J. P. Baukus, H. Y. Itoh, T. Nozaki, T. Masui and T. Abe, Appl. Phys. Lett. 47, 488 (1985).

[6] M. R. Brozcl, E. J. Foulkcs, R. W. Series. W. Winston, and O. J. Marsh, Appl. Phys. Lett. 44, 74 (1984)

[7] M. Skowronski, S. T. Neild, and R. E Kres, and D. T. J. Hurlc, Appl. Phys. Lett. 49, 337 (1986).

[8] O. K. Kim and W. G. Spitzer, J. Appl Kremer, Appl. Phys. Lett. 58, 1545 (1991).

[9] E. Finkman and Y. Nemirovsky, J. Appl. Phys. 50, 3362 (1979); S. Adachi, J. Appl. Phys. 58, R1 (1985).

[10] W. G. Spitzer and H. Y. Fan, Phy, Appl. Phys. 50, 4356 (1979).

[II] J. K. Kung and W. G. Spitzer, Phys. Rev. 106, 882 (1957).

[12] S. C. Baber, Thin Solid Films 72, 201 (1980). Soc. 121, 1482 (1971). 


\subsection{Physical Basis}

4.2.1 Nomarski Microscopy In Nomarski microscopy, two microscopic images of a surface are formed so that they are slightly displaced in space and of opposite phase. Interference bands appear where the images overlap. The physical displacement and the interference bands heighten the visibility of small variations in surface levels.

4.2.2 Scanning Microscopy In scanning microscopy, a spot of light, whose size is limited by diffraction, is scanned over a specimen. The image of the specimen is developed point by point in sequential fashion, to be displayed or stored for analysis. If the specimen is broadly illuminated and scanned in a raster pattern by a point detector (or raster scanned by a point source, with the light sensed by a broad area detector), a two-dimensional image results. In the variation known as confocal scanning, the specimen is illuminated in only a small region at any one time, and a point detector senses light only from that same region. This makes it possible to develop a three-dimensional image. Confocal scanning also enhances resolution.

The light can be sensed by any of several conventional detectors. In the OBIC method, however, the detector is an external circuit that measures the current produced locally by the incident light. Light intensity from a laser of even modest power creates a high density of carriers in the sample, due to electron-hole excitation. The electrons and holes are affected by the electric fields associated with macroscopic defects, such as grain boundaries in polycrystalline silicon, so that the motion of the electrons and holes induces a current which is sensed by an external circuit. Hence, OBIC images clearly show the presence of defects, and map out their locations.

4.2.3 Microspectrophotometry Reflection spectrophotometry depends on the interference pattern caused by reflections from top and bottom surfaces of a transparent film. The equations governing reflection from stratified dielectric media are derived in most optics texts [2]. Microspectrophotometry is normally used for determining the film thickness of a single layer on a substrate or the film thicknesses in a relatively simple multilayer stack. As in ellipsometry, values of the functions $n(\omega)$ and $k(\omega)$ for each of the layers of interest are needed to determine the thicknesses. The advantages of reflectometry relative to ellipsometry are that most of the information is carried in the wavelength dependences, and it is relatively simple to focus the beam down to spot sizes on the order of micrometers [3].

\subsection{Experimental and Teclinical Details}

4.3.1 Nomarski microseopy In Nomarski microscopy, two microscopic images of a surfice are formed by a Wollaston prism. The prism is placed between the eyepiece and the objective of the microscope, as shown in Fig. 8.

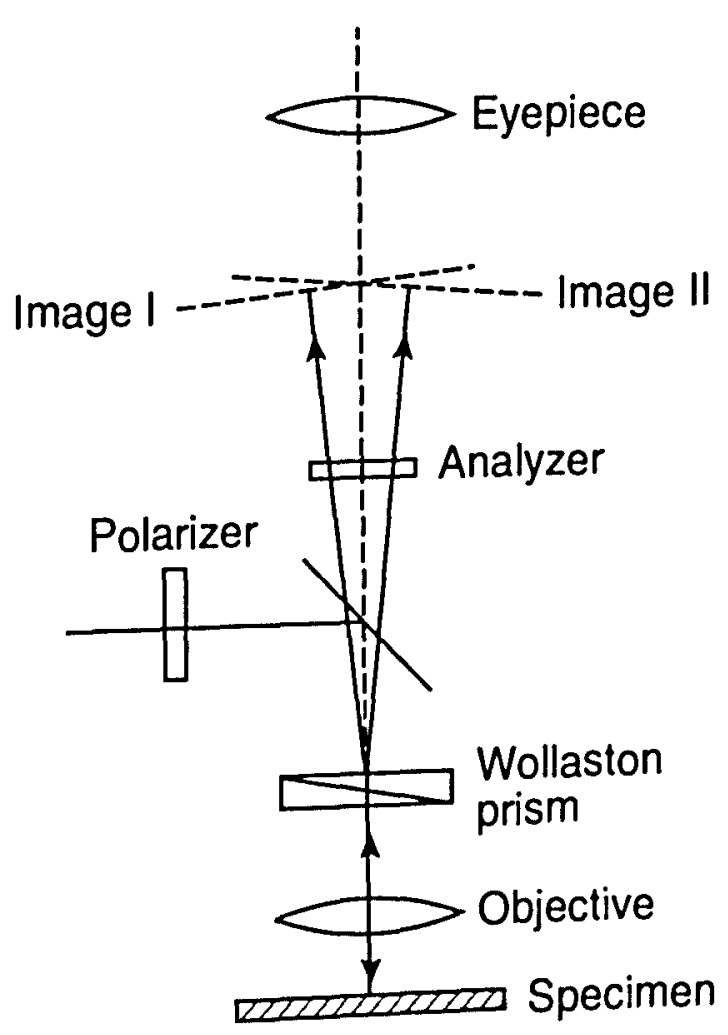

Fig. 8. Schematic diagram of a Nomarski inlerference micto. scope. The Wollasion prism eonsisls of idenlical prisms of crylalline quarlz, one with is oplical axis parallel lo the plane of the paper and the specimen surface, the other perpendiculat to the planc of the paper. (Sec Sec. 4.5, General Refs, Mindin and Modin (1973), fig. 3.t7, p. 130.)

Light traversing the prism is divided into two beams polarized at right angles to each other and diverging by some angle, giving two microscopic im. ages. The microscope includes a polarizer set so that the incident light lies at $45^{\circ}$ to the plane of $v$ bration of the prism. With an analyzer set at right angles to the polarizer, this gives two images of the same intensity hut $180^{\circ}$ apart in phase. Hence, in. terference bands form where the images werlap. These fringes, combined with the displacement of the images, magnify surface variations. The edges of surface features become clearly visible, and the thickness of films deposited on the surface can be found. 
4.3.2 Scanning Microscopy Figure 9 shows the main components of a scanning microscope. It includes a light source, usually a laser; a scanning system, which either moves the laser beam across a fixed sample or moves the sample relative to a fixed optical system; optical elements to focus and manipulate the beam; and a detector. The type of detector used depends on the scanning and imaging methods and on the wavelengths; it may be a single photomultiplier tube or a detector array. In the OBIC method, it is an external circuit that measures the photocurrent.

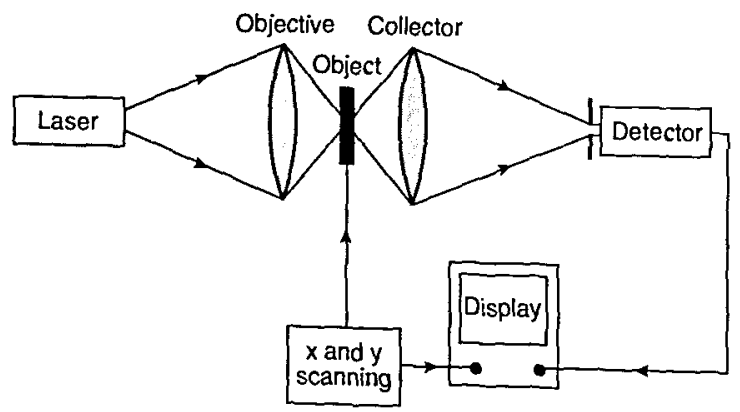

Fig. 9. Schcmatic diagram showing the main clcments of a scanning microscope. (Sce Scc. 4.5, General Refs., Wilson and Shcppard (1984), fig. 1.1, p. 2.)
As stated above, in some systems, the light beam is scanned across a fixed sample. This allows rapid acquisition and display of images; however, there are complications in designing the movable optical system, and in maintaining good image quality. In other designs, the light beam is fixed and the sample is moved to produce the raster pattern. Although these systems are relatively slow, the optical design is simple and produces images of high quality.

The OBIC technique (a typical experimental arrangement is illustrated in Fig. 10) is one of the most important for semiconductor materials and devices, and can readily be implemented with small lasers as sources. A $1 \mathrm{~mW}$ HeNe laser produces $3 \times 10^{15}$ photons per second. Based on a calculation using typical parameters for electron-hole generation in a semiconductor, this intensity is enough to generate a large density of electron-hole pairs, about $10^{210} \mathrm{~cm}^{-3}$. The electric fields associated with defects or doped regions separate the electron and hole in each pair. These separated carriers can induce a current by flowing through an appropriate external circuit. (Depending on whether the sample includes a p-n junction or not and on the nature of the circuit, either photovoltages or photocurrents can be measured.)

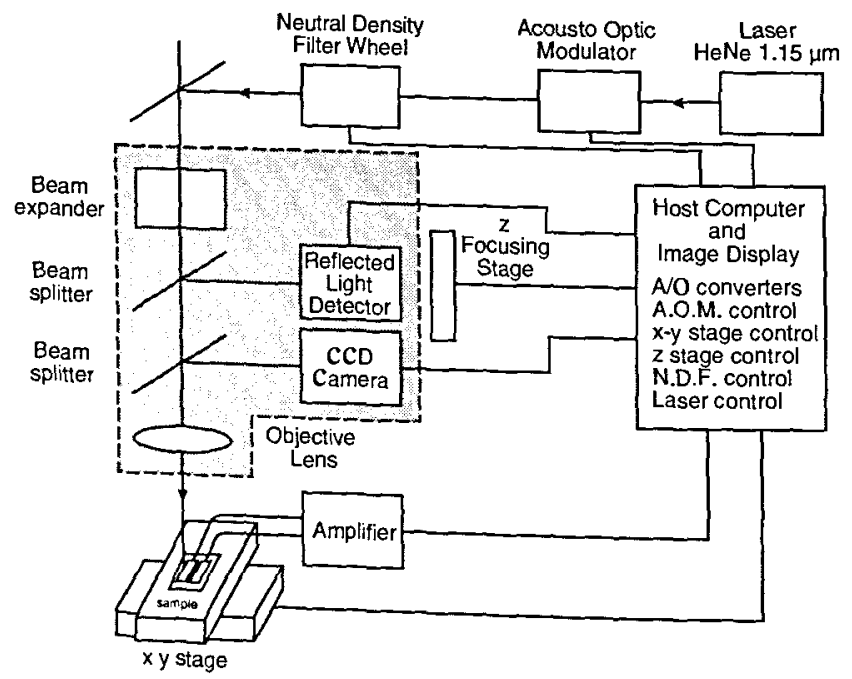

Fig. 10. Schematic diagram of an optical-beam-induecd current (OBIC) system, also callcd LBIC (lascr-beam-induced current). (Sce
Scc. 4.5, General Refs. Moore, fig. 1.) 
Scanning methods can be used equally well in the visible and in the infrared regions. In one typical infrared system, the source is a semiconductor laser operating at $1.3 \mu \mathrm{m}$ wavelength (giving a spot diameter of about $2 \mu \mathrm{m}$ ), with detection accomplished by germanium photodiodes. The sample is mechanically moved to produce raster scanning, and the resulting images are taken at resolutions of 512 pixels by 512 pixels.

4.3.3 Microspectrophotometry Interference of light waves reflected from each interface of a multilayer film structure determines the reflectance of the structure. The reflectance spectrum depends on angle of incidence of the radiation, the refractive indices of the media, polarization of the radiation, and film thicknesses [4]. Whereas the same equations describing reflection and transmission apply in both ellipsometry and reflectance spectrophotometry, the problem is somewhat simplified in the case of reflectometry, where polarization is usually ignored. Normally, the reflected light intensity is recorded versus wavelength. Then, the thicknesses are calculated by fitting measured spectra to calculated spectra based on a model of the layer structure and known dielectric constants. Measurements can also be made of the reflectance versus polarization angle or versus angle of incidence, but this is not normally done in microscopic measurements because these parameters are difficult to change systematically within the microscope environment. The most frequent application of microspectrophotometry is the determination of thicknesses of simple dielectric stacks on a substrate; but microspectrophotometry can also be used like ellipsometry to find the dielectric function of film layers and, hence, film layer composition [4]. Because of the relaxed constraint on the angle of incidence and the relative speed of processing data, microspectrophotometry is an ideal way to map the uniformity of wafer film thickness.

\subsection{Illustrative Applications}

Figure 11 shows the power of OBIC imaging to detect flaws in semiconductor materials such as silicon, even when the material is incorporated in an operating device such as a transistor. Figure 12 shows an infrared scanning system micrograph of oxide particles embedded in Czochralski-grown silicon, even displaying those particles smaller than the infrared beam diameter of $2 \mu \mathrm{m}$. By focusing to different depths in the sample, it is possible to obtain some depth-dependent information as well.

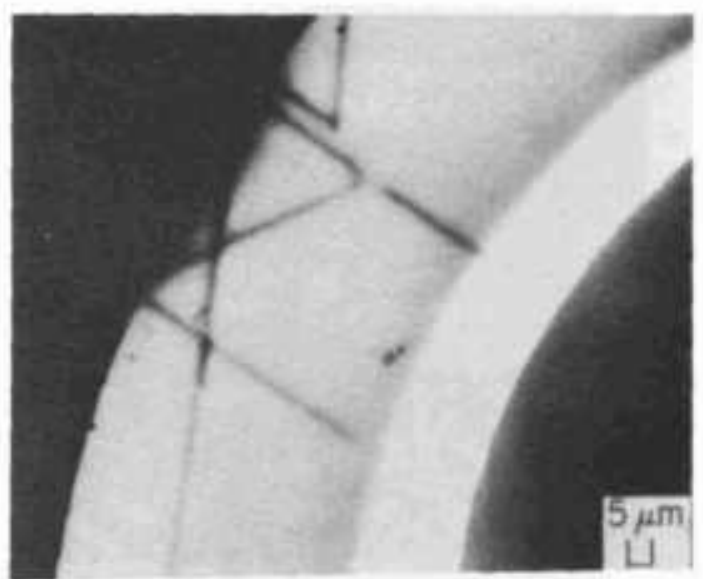

Fig. J1. An $O B \mid C$ image formed by monitoring the emitterbase current in a silicon transistor while a laser beam is scanned across the eransistor. The dark straigh lines are lines of dislocitions in the silicon. (Sec Sec. 4.5, General Refs, Wilson and Sheppard (1984), fig, 1.6, p. 8.)

\subsection{References}

[1] G. O.Ziao, T. R. Corle, and G.S. Kino, Rcal-lime confocal scanning optical microscope, Appl. Phys. Lett. 53, 716 (1988).

[2] M. Born and E. Wolf, Principles of Optics, Pergamon Press, Niw York (1975) p. 61.

[3] P. Burggraf, How thick are your thin films?, Semiconductor International (1988) p. 96.

[4] S. E. Stokowski, Mcasuring refractive indices of films on semiconductors by microreflectomery. in Integrated Circuit Melrology, Inspection, and Process Conerel IV, Proccedings SPIE, W. 11. Arnold, ed., SPIE, Bcllingham. Washington (1990) p. 253.

\section{General}

Microseopy of Semiconducting Marsrials, Institute of Phywion Conference Proc. 60, A. G. Cullis and D. C. Joy, edr. Insirute of Physics, Adam Hilger, Bristol (1981).

Microscupy of Scmiconducling Matcriala, Insuttute of Phywics Confurence Proc. 67, A. G. Cullis, S. M. Davisun, and G. R Booker, eds. Institute of Physics, Adam Illiger, Bristol (J983)

Microscopy of Semiconducting Materials, Insuilute of Physica Conference Proc. 76, A. G. Cullis and D. B. Holl, eds. Adam Hilger, Bristol (1985).

Microscopy of Semicondueting Materials. Invitute of Physic Conferctace Proc. 87, A. G. Cullis and P. D. Auguviun eda. Invis futc of Physics, Adam Jlilger. Bristol (1987).

Microscopy of Semiconducting Matcrials. Insunute of Ptratic Conferenec Proc, 100, A G. Cullis and ). L. Ilutchinuon, eds. Instisutc of Physics, Adam llilger, Bristol (1959) 


\section{Journal of Research of the National Institute of Standards and Technology}
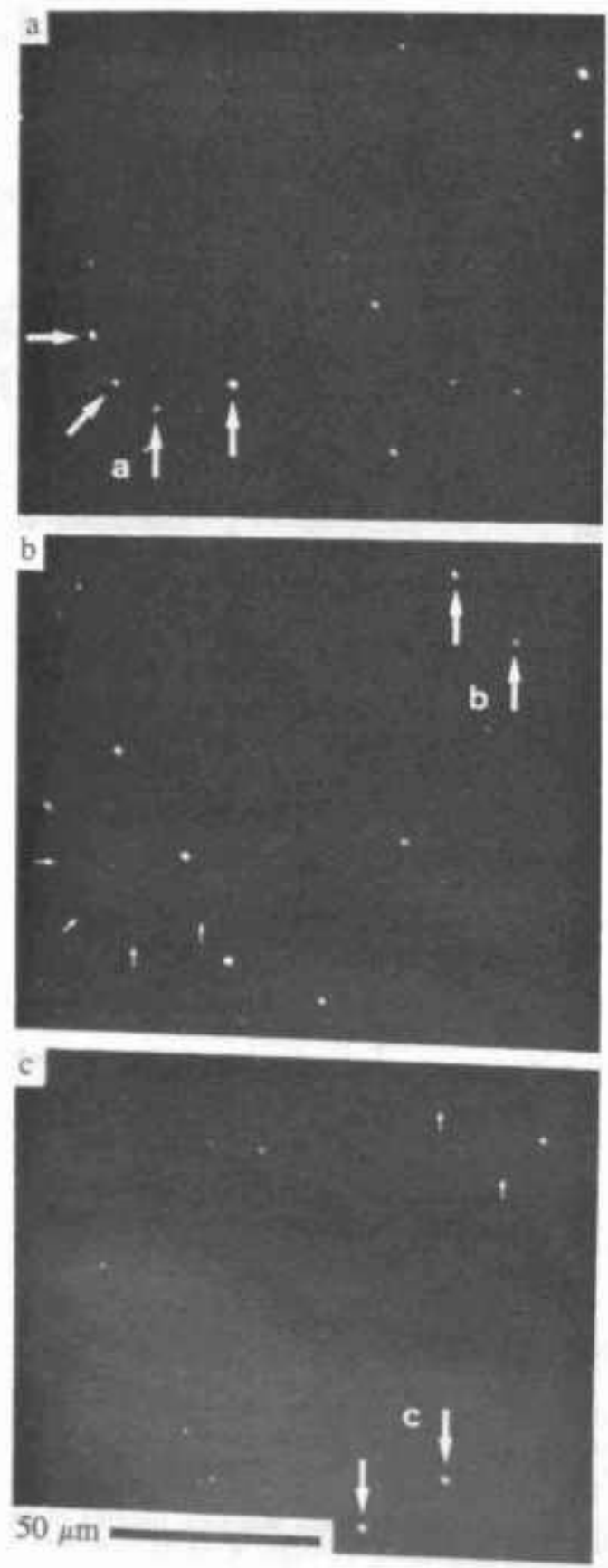

Fig. 12. Infrared scanning microscope images of oxide particles in heat-treated (100) Czochralski silicon. The microscope used a scmiconductor laser cmitting at $1.3 \mu \mathrm{m}$, to give a spot sizc of -2 $\mu \mathrm{m}$. Particles of this size or grcater are directly imaged. Smaller particles can still be secn, although as spots $2 \mu \mathrm{m}$ across, because the system can detcet intensity variations of about $0.5 \%$. The depth of focus is $30 \mu \mathrm{m}$. Pancls (b) and (c) show successively deeper probes into the sample, relative to Panel (a). The focal plane is $60 \mu \mathrm{m}$ decper in Panel (b) and $120 \mu \mathrm{m}$ decper in Pancl (c). The sets of oxide images marked "a," "b," and "c" can be followed in and out of focus through the panels. (See Sec. 4.5, Applications Refs. Laczik. Booker, Falster, and Shaw (1989),
fig. I, p. 808.)
Microscopy of Semiconducting Matcrials, Institute of Physics Conference Proc. I17, A. G. Cullis and N. J. Long, cds., Institute of Physics, Bristol (1991).

S. Hildebrandt and W. Hergert, Unificd theoretical description of the CL, EBIC, PL, and EBIC contrast profile arca of an individual surfacc-parallel dislocation. Phys. Stat. Sol (a) 119, 689699 (1990).

R. Keeler, Confocal microscopes, R\&D Magazinc (April 1991) pp. $40-42$.

H. Modin and S. Modin, Mctallurgical Microscopy, John Wilcy, Ncw York (1973).

T. Wilson and C. Sheppard, Theory and Practice of Scanning Optical Microscopy, Academic Press, London (1984).

\section{Applications}

J. Bajaj, L. O. Bubulac, P. R. Newman, and W. Tennant, Spatial charactcrization of semiconductors using laser beam induced current (LBIC), in Modern Optical Characterization Techniques for Semiconductors and Semiconductor Devices, Procecdings SPIE Vol. 794, O. J. Glembocki, F. H. Pollak, and J. J. Song, cds., SPIE, Bellingham, Washington (1987) pp. 136-I4I.

J. Bajaj, W. E. Tenuant, and P. R. Newman, Laser beam induced current imaging of surface nonuniformity at the $\mathrm{HgCdTe} / \mathrm{ZnS}$ interface. J. Vac. Sci. Technol. A 6, 2757 (1988).

S. Haq, G. Hobson, K. E. Singer, W. S. Truscott, and J. O. Williams, A transmission clcctron microscopy investigation of $\mathrm{GaAs}_{1-y} \mathrm{Sb}_{\mathrm{y}}$-GaAs supcrlattices grown by molccular beam cpitaxy, in Microscopy of Scmiconducting Matcrials, Institute of Physies Conference Proc. 100, A. G. Cullis and J. L. Hutchinson, eds., Adam Hilger, Bristol (1989) pp. 337-341.

P. Kidd, G. R. Booker, and D. J. Stirland, 3-D distribution of inhomogeneitics in LEC GaAs using infra-red laser scanning microscopy, in Microscopy of Semiconducting Materials, Institutc of Physics Conference Proc. 87, A. G. Cullis and P. D. Augustus, eds., Adam Hilgcr, Bristol (1987) pp. 275-280.

Z. Laczik, G. R. Booker, R. Fulster, and N. Shaw, Investigation of precipitate particles in Si and CuTe ingot material using the scanning infrared-red microscope (SIRM), in Microscopy of Scmiconducting Materials, Institutc of Physies Conference Proc. 100, A. G. Cullis and J. L. Hutchinson, eds., Adam Hilger, Bristol (1989) pp. 807-812.

Y-C., Lu, R. K. Routc, D. Elwcll, and R. S. Fcigclson, Etch pit studies in CuTe erystals. J. Vac. Sci. Technol. A 3, 264 (1985).

J. L. Mariani, B. Pichaud, F. Minari, and S. Martinuzzi, Direct decermination of the recombination activity of dislocations in FZ silicon by LBIC measurements, in Microscopy of Semiconducting Materials, Institute of Physics Conference Proc. 100, A. G. Cullis und J. L. Hutchinson, eds., Adam Hilger, Bristol (1989) pp. 801-806.

C. J. L. Moore, J. Hennessy, J. Bajaj, and W. E. Tennant, Finding faults in focal plane arrays, Photonics Spectra (September 1988) pp. 161-166. 
M. Ogura, M. Tajima, and Y. Tokumaru, Seanning optieal fiber mieroseope for high resolution laser beam indueed eurrent images of semiconductor materials, in Materials Charaeterization, Materials Researeh Society Symposia Proeeedings Vol. 69, N. Cheung and M.-A. Nieolet, eds., Materiats Researeh Soeiety, Pittsburgh, Pennsylvania (1986) pp. 251-256.

D. J. Stirland, P. Kidd, G. R. Booker, S. Clark, D. T. J. Hurle, M. R. Brozel, and I. Grant, The behaviour of arsenie-rich defeets in quenched semi-insulating GaAs, in Mieroseopy of Semieondueting Materials, Institute of Physies Conferenee Proe. 100, A. G. Cullis and J. L. Hutehinson, eds., Adam Hilger, Bristol (1989) pp. 373-378.

\section{Modulation Spectroscopy}

\subsection{Introduction}

Modulation spectroscopy is a sensitive technique which can determine fine details of interband transitions in semiconductors. In semiconductor superlattices and other microstructures, detailed knowledge of the complex interband transitions can be used to characterize quantum well widths, potential barrier heights and widths, electric fields, and the amount of strain in strain layer systems.

\subsection{Physical Basis}

The principle behind modulation spectroscopy is that a periodic physical perturbation applied to a sample elicits the derivative of the sample's optical response to that perturbation. The derivative feature amplifies weak features in the response function and suppresses large constant background levels. This gives modulation methods very high sensitivity to small spectral features that are invisible in conventional spectroscopy.

To illustrate the origin of the derivative response, consider the reflectivity $R$ of a sample. This depends on the sample's dielectric function, which depends on many physical properties. For example, the dielectric function depends on an applied electric field $E$; hence, $R$ also depends on $E$. If the applied electric field has a dc component $E_{0}$ and a small ac component $E_{1} \cos \Omega t(\Omega$ is the modulation angular frequency), the reflectivity can be written as $R(E)=R\left(E_{0}+E_{1} \cos \Omega t\right)$. If $E_{1}<<E_{0}$, this expression can be expanded in a Taylor series, where only the first two terms are kept; that is

$$
R(E) \cong R\left(E_{0}\right)+\frac{\mathrm{d} R}{\mathrm{~d} E}\left(E_{1} \cos \Omega t\right) .
$$

The first term depends on $E_{0}$ but not on time, whereas the second term is a periodic function of

time at the modulation frequency $\Omega$. Hence, the ac portion of the reflectance at frequency $\Omega$ cinl be de. tected with a lock-in amplifier; this signal is proportional to the derivative $\mathrm{d} R / \mathrm{d} E$. Thus, smill structures in the optical spectrum of $R(E)$ are enhanced, even with the sample at room temperature. A periodic perturbation can be applied to any physical property affecting the sample's opticil response. Examples are electroreflectance, where a periodic electric field is applied to a sample white its reflectance spectrum is measured; and photoreflectance, where optically injected cirriers from a chopped laser beam modulate the "built-in" surface or internal electric fields, therelyy modulating the reflectance of the sample. Other forms of modulation spectroscopy have been reviewed by $A$ spnes [1]. The following discussion concentrates on electroreflectance and photoreflectance, two forms of modulation spectroscopy currently in common usage. Because photoreflectance results from the modulation of "built-in" electric fields, this discussion applies generally to either electroreffectince or photoreflectance.

The enhancement of spectroscopic structures that appear at energies corresponding to energy gaps and other critical points in the joint density of states of the material under study is one useful re. sult of modulation methods. The method lecomes more useful still when the measured spectral line shapes can be connected to microscopic parameters through theory. The relationship that makes this connection is [2]

$$
\frac{\Delta R}{R}=\alpha \Delta \epsilon_{1}+\beta \Delta \epsilon_{3},
$$

where $\Delta R$ is the change in reflectivity due to the applied modulation, $\Delta \epsilon_{1}$ and $\Delta \epsilon_{2}$ are the changes in the real and imaginary parts, respectively, of the complex dielectric function $\epsilon=\epsilon_{1}+i \epsilon_{i}$, and $\alpha$ and $\beta$ are called the Seraphin coefficients. Near the energy gap of a bulk sample, $\beta=0$; however, for $\mathrm{com}$ plex microstructures where interference effects occur, both $\alpha$ and $\beta$ need to be considered, and hence $\Delta \epsilon_{1}$ and $\Delta \epsilon_{2}$ must both be known. These can be calculated from general band theory and from dielectric function theory. In the case of electrore. flectance and photoreflectance, different spectral line shapes are obtained, and conconittintly different analyses are required, depending on the magnitude of the electric field. The modulation field is usually described in terms of three regimes [2]: high field (Stark effect), intermediate field (FranzKeldysh effect), or low field. The high field case is 
not usually studied under modulation conditions, as a high electric field breaks down the normal selection rules and results in a Stark shift of the band structure. The analysis of spectra based on intermediate and low field theories is discussed in reference to representative spectra, in the illustrative applications section below.

\subsection{Experimental and Technical Details}

A modulation measurement requires a light source, a monochromator, and a detector as in conventional spectroscopy, and a means to apply the modulation to the sample. These elements are shown in Fig. 13. The source can be an incandescent or discharge lamp. Generally, a monochromator of $0.25 \mathrm{~m}$ focal length provides adequate energy resolution, but higher resolution may be needed in some cases.

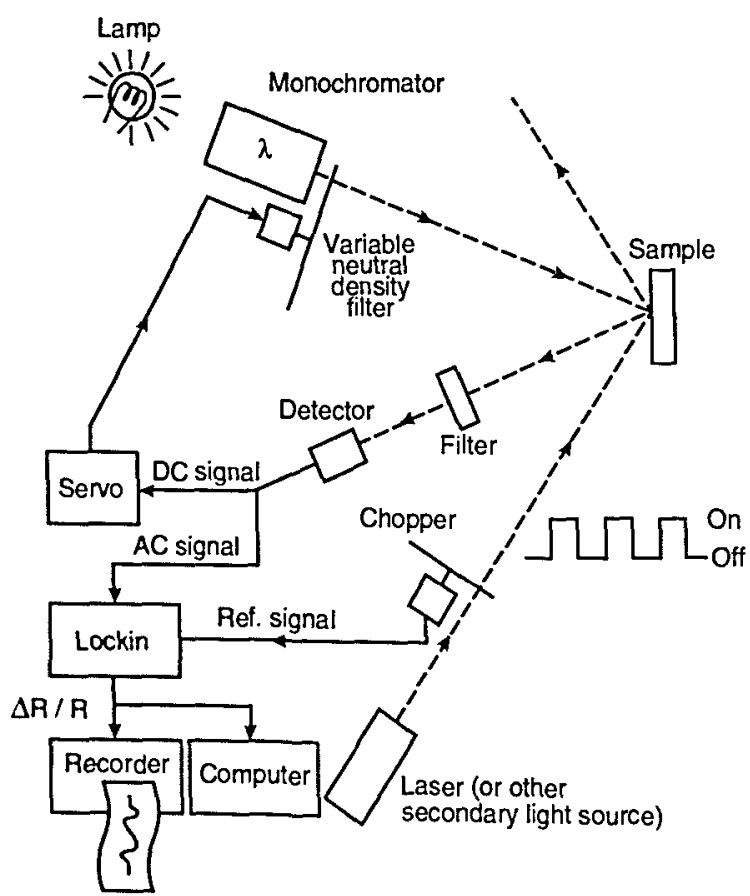

Fig. 13. Diagram of a photoreflectance spectrometer, illustrating lamp with following optics and electronics to obtain the spectrum, and a laser to supply modulated light. The variable neutral density filter holds the constant part of the detected signal independent of wavelength, facilitating evaluation of the ratio of $\Delta R / R$. (See Sec. 5.5, General Refs., Pollak and Glembocki (1988), fig. 4, p. 25.)

The light reflected from the sample is detected by a photomultiplier tube or a photodiode. It contains a steady $(\mathrm{dc})$ component $R I_{0}\left(I_{0}\right.$ is the incident light intensity) and a periodically modulated (ac) component $\Delta R I_{0}$. To obtain $\Delta R / R$, the dc signal and the ac signal must be separately measured and then a ratio of these signals is taken. It is also possible to electronically hold the dc signal (corresponding to $R I_{0}$ ) constant during the measurement. This can be done by a feedback loop that changes the gain of the detector to keep its dc output constant, or, as shown in Fig. 13, by mounting a circular continuously variable neutral density filter on a servo motor and inserting it before the sample.

For photoreflectance, light from a modulated optical source such as a laser, whose photon energy exceeds the sample's energy gap, impinges on the sample. For electroreflectance of a doped semiconductor, the varying electric field can be applied between an ohmic contact on the sample's back surface, and a transparent gate electrode on the front of the sample; $5 \mathrm{~nm}$ to $10 \mathrm{~nm}$ of deposited gold or aluminum is an adequate electrode. A second method is to put the sample in an electrolyte such as a $\mathrm{KCl}$ solution, or an acidic solution. The resulting electric field at the sample surface can be changed by varying a voltage applied between the sample and a platinum counter electrode. Photoreflectance and electroreflectance spectroscopy both provide highly detailed spectra even at room temperature, so that sample cooling is usually not needed.

\subsection{Illustrative Applications}

Figure 14a shows the sensitivity of modulation spectroscopy, by comparing the reflectivity spectrum of GaAs in the interband region to the much more detailed $\Delta R / R$ spectrum obtained by electroreflectance. Figure 14a is illustrative of the low field case. Here the spectra near the energy gap can be fitted using [3]

$$
\frac{\Delta R}{R}=R\left[\mathrm{e}^{i \theta}\left(\hbar \omega-E_{\mathrm{g}}+i \Gamma\right)^{-m}\right],
$$

where $\hbar \omega$ is the photon energy, $E_{\mathrm{g}}$ is the gap energy, $\theta$ is the phase factor, $\Gamma$ is the lifetime broadening parameter, and the quantity $m$ takes on the values 2, 2.5, and, 3 for excitonic, three-dimensional, and two-dimensional critical points, respectively. Hence, the critical point type and energy can be determined from fitting this line shape. Aspnes [3] has also developed a "three-point" method for extracting critical point energies which for simple spectra eliminates the need for a full spectrum fit.

Shown in Fig. 14b [4] is the photoreflectance spectra of a moderately n-type doped 


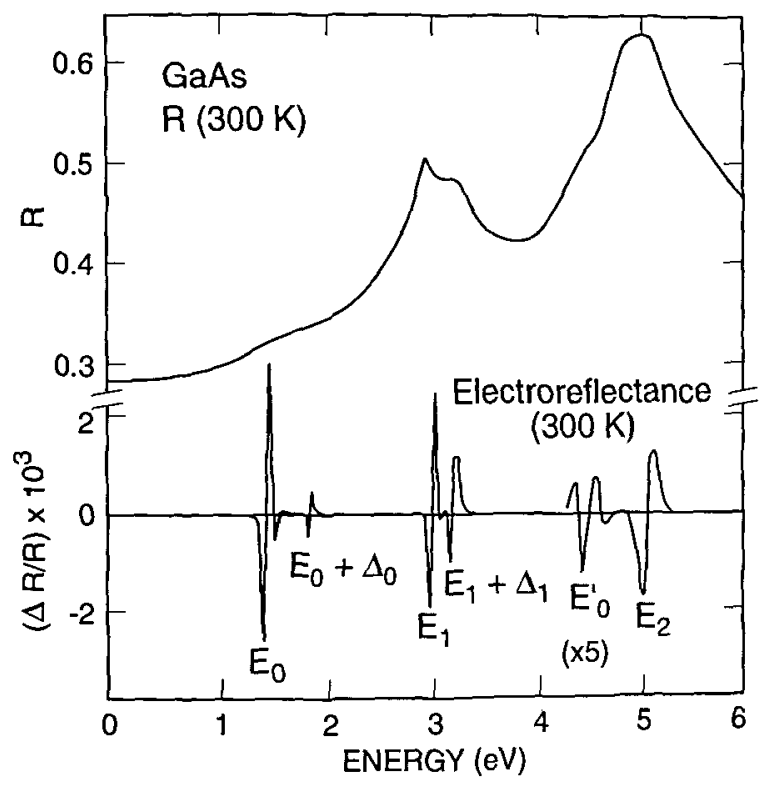

Fig. 14a. Conventional interband reflectivity spectrum for GaAs at $300 \mathrm{~K}$, compared to the intcrband $\Delta R / R$ spectrum at 300 $\mathrm{K}$ obtained by electror eflectance. The broad features in the plot for reflectivity $R$, such as the shoulder at the gap energy $E_{0}$, become obvious sharp tines in the $\Delta R / R$ data which lic on a baseline of zero signal. Structurc at $E_{0}+\Delta_{0}$ which was invisible in the reflectivity spectrum is apparent in the $\Delta R / R$ curve. (Sce Sec. 5.5, Generat Rcfs., Pollack and Glcmbocki (1988), fig. l, p. 25.)

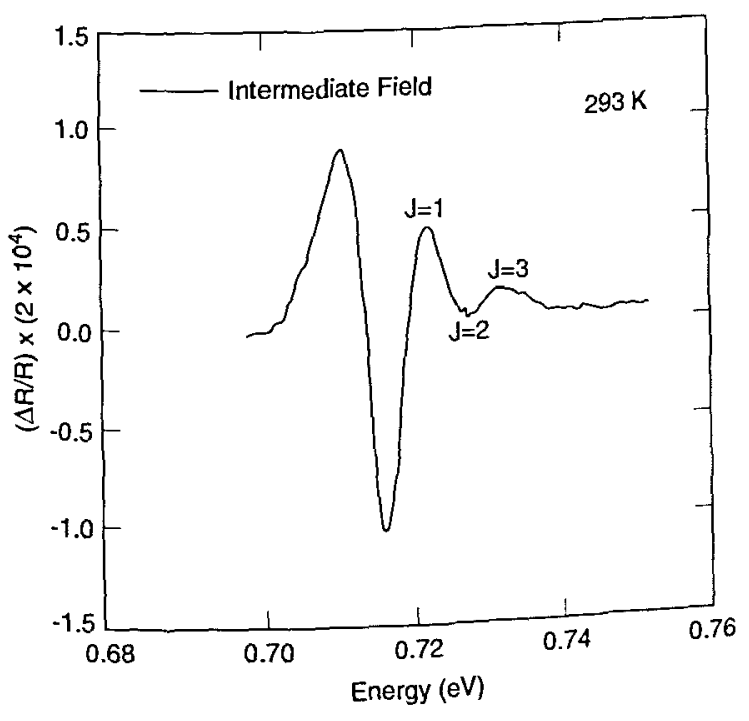

Fig. 14b. Photoreflectance spcetra for the intermediatc ficld case for a moderately doped sample of $\operatorname{InGaAs} / \mathrm{lnP}$ with labeled extrema $(J=1,2,3)$.

$\left(\sim 1 \times 10^{16} \mathrm{~cm}^{3}\right)$ sample of $\operatorname{In}_{0.53} \mathrm{Ga}_{0.47}$ As illustrating the intermediate field line shape. This case can be identified by the presence of oscillatory behavior, the so-called Franz-Keldysh oscillations at energies greater than the energy gap of the matcrial. Modulation intensities are usually greater for the high field case than for the low ficld case. Matcrials information (electric fields and energy gap values) is typically extracted from Franz-Keldysh oscillations using the Aspnes asymptotic approximation [5]

$$
\begin{gathered}
\frac{\Delta R}{R}=\left(h \omega-E_{8}\right)^{-1} \exp \frac{I\left(h \omega-E_{g}\right)^{3 / 2}}{(h \Omega)^{3 / 2}} \\
\quad \times \cos \left[\theta+\frac{2}{3}\left(\frac{h \omega-E_{8}}{h \Omega}\right)^{3 / 2}\right],
\end{gathered}
$$

where $\theta, I$, and $E_{\mathrm{g}}$ are defined above, and $h / \Omega$ is the electro-optic parameter $\left[e^{2} E^{2} h^{3} / 32 \pi^{2} \mu\right]^{1 / 4}$. Here, $c$ is the electron charge, $E$ is the de electric field, $h$ is Planck's constant, and $\mu$ is the reduced interland effective mass. Since successive extrema represent a change of $\pi$ in the argument of the cosine term in Eq. 15, the energy of the $j$ th extremal [5] can be written as

$$
j \pi=0+\frac{2}{3}\left[\frac{\left(h \omega-E_{q}\right)}{h \Omega}\right]^{32} .
$$

Hence, the phase factor and electro-optic energy can be obtained from the intercept and slope of a plot of $\left.\left(\hbar \omega-E_{\varepsilon}\right)\right)^{3 / 2}$ vs $j .1 t$ is noteworthy that the electric field in a structure under study can be extracted from the electro-optic energy, requiring only independent knowledge of the effective mass of the material. Hence, electroreflectance and pho. toreflectance provide very important methods for nondestructive determination of surface and junction electric fields. These fields can, in turn, be related to doping densities in a space charge region [6] through the Schottky equation.

Figure 15 presents photoreflectance data used to characterize a GaAs/Al ${ }_{124} \mathrm{Ga}_{4}, \mathrm{As}$ mulliple quan. tum well. The chopped liser bcam, $100 \mu \mathrm{m}$ in di. ameter, had been moved along the structure to give spectra from different spatial regions. Each of the resulting spectra was theoretically fitted, to determine how the well width and $\mathrm{A} / \mathrm{mole}$ fraction value changed with position over a distance of $1.4 \mathrm{~cm}$. 


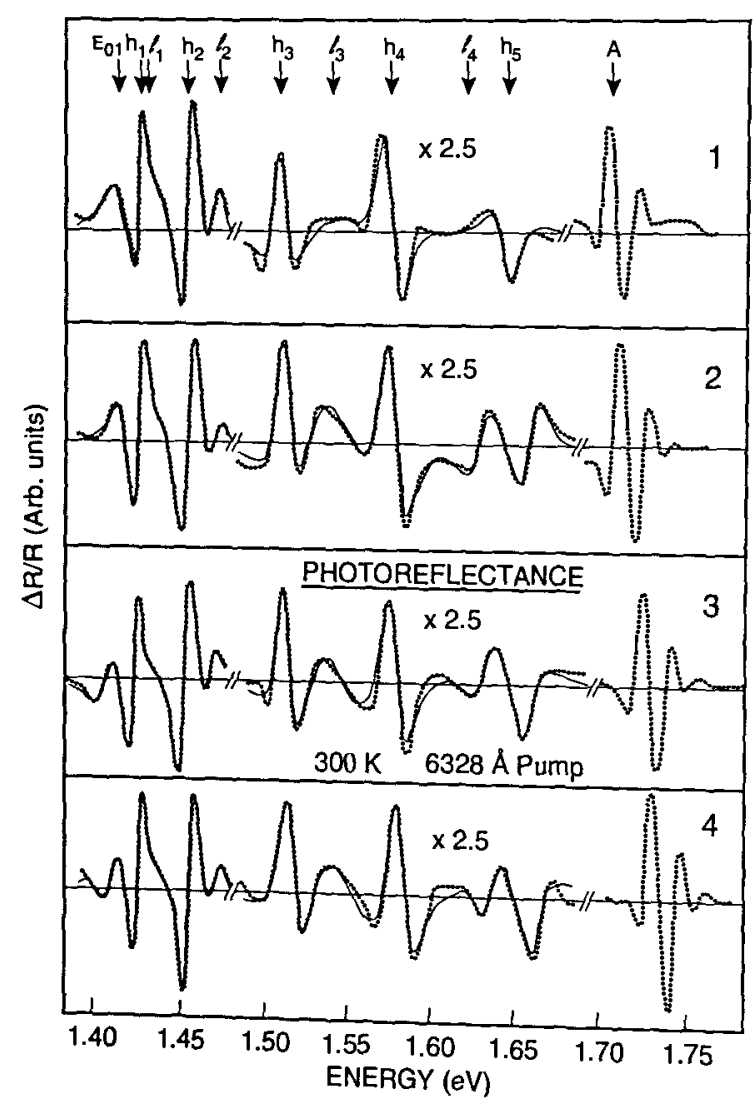

Fig. 15. Photoreflectance spectra of $\mathrm{GaAs} / \mathrm{Al}_{x} \mathrm{Ga}_{1-x}$ As multiple quantum well (MQW) with nominal $x$ value 0.24 , and nominal barrier and well thickness of $15 \mathrm{~nm}$ and $22 \mathrm{~nm}$, respectively. Spectra (1) to (4) were measured at locations spaced $0.47 \mathrm{~cm}$ apart along a straight line. In each, the peak at $1.42 \mathrm{cV}$ marked $E_{01}$ comes from the direct gap of the GaAs substrate, the peak marked " $A$ " near $I .72 \mathrm{eV}$ comes from the direct gap of the $\mathrm{Al}_{x} \mathrm{Ga}_{1-x} \mathrm{As}$ barriers, and the remaining features marked $l_{n}$ and $h_{n}(n=1,2,3 \ldots)$ between 1.43 and I.68 eV come from light and heavy hole interband transitions characteristic of the MQW enby bands. The $\mathrm{Al}_{x} \mathrm{Ga}_{1-x} \mathrm{As}, h_{1}$, and $l_{1}$ features shift with spatial position. Fits to the data show that the well width ranges from $21.4 \mathrm{~nm}$ to $21.0 \mathrm{~nm}$, and $x$ ranges from 0.225 to 0.247 , between Refs., Parayanthal, $1.4 \mathrm{~cm}$ apart. (See Sec. 5.5, Applications Beard (I986), fig. 1, p. 126I)

Table 5 presents the sensitivities to typical quantities measured by photoreflectance spectroscopy such as composition, stress, electric field strength, surface photovoltage, and doping density. For more specific details, the reader should refer to the cita-
tions given in the table.

\subsection{References}

[1] D. E. Aspnes, Modulation spectroscopy/elcctric field effects on the diclectric function of semiconductors, in Handbook on Semiconductors, Vol. 2, T. S. Moss and M. Balkanski, eds., North-Holland, New York (I980) p. 109.
[2] B. O. Seraphin and N. Bottka, Franz-Keldysh effect of the refractive index in semiconductors, Phys. Rev. 139 A560 (1965).

[3] D. E. Aspnes, Third-derivative modulation spectroscopy with low-field elcctroreflectance, Surface Science 37, 418 (1973).

[4] J. P. Estrera, W. M. Duncan, Y. C. Kao, H. Y. Liu, and E. A. Beam, Systematic optical and $x$-ray study of $\operatorname{In}_{\mathbf{x}} \mathrm{Ga}_{1}-{ }_{x} A s$ on InP, J. Electronic Materials 20, 983 (1991).

[5] D. E. Aspnes and A. A. Studna, Schottky-barrier electroreflectance: application to GaAs, Phys. Rev. B 7, 4605 (I973).

[6] W. M. Duncan and A. F. Schreiner, Surface state study of ion implanted GaAs (Se) from photoreflectance, Solid State Communications 3I, 457 (1979).

\section{General}

J. I. Pankove, Optical Processes in Semiconductors, Prentice Hall, Englewood Cliffs (1971) pp. 391-407.

F. H. Pollak and O. J. Glembocki, Modulation spcctroscopy of semiconductor microstructures: an overview, in Spectroscopic Characterization Techniques for Semiconductor Technology III, Procecdings SPIE Vol. 946, O. J. Glembocki, F. H. Pollak, and F. Ponce, eds., SPIE, Bellingham, Washington (1988) pp. 2-35.

\section{Applications}

P. M. Amirtharaj, J. H. Dinan, J. J. Kennedy, P. R. Boyd, and O. J. Glembocki, Photoreflectance study of $\mathrm{Hg}_{0.7} \mathrm{Cd}_{0.3} \mathrm{Te}$ and $\mathrm{Cd}_{x} \mathrm{Zn}_{1-x} \mathrm{Tc} \mathrm{E}_{1}$ transition, J. Vac. Sci. Technol. A 4, 2028 (I986).

R. N. Bhattacharya, H. Shen, P. Parayanthal, and F. H. Pollak, Electroreflectance and photoreflectance characterization of the space charge region in semiconductors: ITO/InP as a model system, in Modern Optical Characterization Techniques for Semiconductors and Semiconductor Devices, Proceedings SPIE Vol. 794, O. H. Glembocki, F. H. Pollak, and J. J. Soong, eds., SPIE, Bellingham, Washington (1987) pp. 81-87.

R. C. Bowman, R. L. Alt, and K. W. Brown, Photoreflectance spectroscopy studies of alloy composition and ion implant damage in zincblende-type semiconductors, in Modern Optical Characterization Techniques for Semiconductors and Semiconductor Devices, Proceedings SPIE Vol. 794, O. H. Glembocki, F. H. Pollak, and J. J. Soong, eds., SPIE, Bellingham, Washington (1987) pp. 96-I04.

R. C. Bowman, D. N. Jamicson, and P. M. Adamson, Optical and structural characterization of boron implanted GaAs, in Spectroscopic Characterization Techniques for Semiconductor Technology 1II, Proceedings SPIE Vol. 946, O. J. Glembocki, F. H. Pollak, and F. Ponce, eds., SPIE, Bellingham, Washington (1988) pp. 65-75.

J. P. Estrera, W. M. Duncan, Y. C. Kao, H. Y. Liu, and E. A. Beam, Systematic optical and $x$-ray study of $\operatorname{In}_{x} \mathrm{Ga}_{1-x}$ As on $\ln$, J. Electronic Materials 20, 983-987 (I991).

O. J. Glembocki, Ellipsometric-electrolyte electro-reflectance study of the $\mathrm{Si} / \mathrm{SiO}_{2}$ interface, in Spectroscopic Characterization Techniques for Seniconductor Technology, Proceedings SPIE Vol. 452, F. H. Pollak and R. S. Bauer, eds., SPIE, Bcllingham, Washington (1983) pp. 130-I41. 
O. J. Glembocki and B. V. Shanabrook, Photoreflcctance characterization of microstructures using a dye laser system, in Modern Optical Characterization Techniques for Scmiconductors and Semiconductor Devices, Proceedings SPIE Vol. 794, O. H. Glembocki, F. H. Pollak, and J. J. Soong, eds., SP1E Bellingham, Washington (1987) pp. 74-80.

R. Glosser and N. Bottka, Comparative response of elcctroreflectance and photoreflectance in GaAs, in Modcrn Opticat Characterization Techniques for Semiconductors and Scmiconductor Devices, Proceedings SPIE Vol. 794, O. H. Glcmbocki, F. H. Pollak, and J. J. Soong, eds., SP1E, Bellingham, Washington (1987) pp. 88-95.

T. K. Gupta, Effective bandgap shrinkage measurement in siljcon sotar eell by electroreflectance method, in Spectroscopic Characterization Techniques for Semiconductor Tcchnology It1, Proceedings SPIE Vol. 946, O. J. Glembocki, F. H. Pollak, and F. Ponce, eds., SPIE, Bellingham, Washington (I988) pp. 76-81.

B. K. Janousek and R. C. Carscallen, Approaches to enhancing the sensitivity of direct coupled photoacoustic spectroscopy as applied to GaAs, in Spectroscopic Characterization Techniqucs for Semiconductor Technology, Proceedings SPIE Vol. 452, F. H. Pollak and R. S. Baucr, eds., SPIE, Bcllingham, Washington (1987) pp. I2I-I27.

C. E. Jones, M. E. Boyd, W. H. Konkel, S. Perkowitz, and R. Braunstein, Noncontact electrical characterization of epitaxial HgCdTe, J. Vac. Sci. Technol. A 4, 2056-2060 (I986).

Y. R. Lee, A. K. Ramdas, F. A. Chambcrs, J. M. Mcesc, and L. R. Ram Mohan, Piezomodulated clectronic spcctra of scmiconductor heterostructures: GaAs/AIGaAs quantum well structures, in Spectroseopic Characterization Teehniques for Semiconductor Technology, Proceedings SP1E Vol. 452, F. H. Pollak and R. S. Bauer, eds., SPIE, Bellingham, Washington (1987) pp. 105110.

T. W. Nee, T. L. Cole, A. K. Green, M. E. Hills, C. K. Lowe-Ma, and $V$. Rehn, Infrared-wavelength modulation spectra of InGaAs grown by MBE and LPE, in Spcctroscopic Charactcrization Techniques for Semiconductor Technology, Procecdings SP1E Vol. 452, F. H. Pollak and R. S. Bauer, cds., SPIE, Bcllingham, Washington (I987) pp. I42-15I.

G. Niquet, J. F. Dufour, G. Chabrier, M. Q'Jani, and P. Vcrnicr, Characterization by electroreflectance of th in films and thin film interfaces in layered structures, in Modcrn Optical Charactcrization Techniques for Scmiconductors and Semiconductor Devices, Proceedings SP1E Vol. 794, O. H. Glembocki, F. H. Pollak, and J. J. Soong, eds., SPIE, Bcllingham, Washington (I987) pp. 1I1-1I5.

P. Parayanthal, H. Shen, F. H. Pollak, O. J. Glembocki, B. V. Shanabrook, and W. T. Beard, Photoreflectance of GaAs/ GaAlAs multiple quant um wells: topographical variations in barricr height and well width, Appl. Phys. Lett. 48, 1261-1263 (1986).

U. K. Reddy, G. Ji, R. Houdre, H. Unlu, D. Huang, and H. Morkoc, Study of GaAs/AIGaAs and InGaAs/GaAs multiplc quantum wells grown on non-polar substrates by photorcflectance, in Modcrn Optical Characterization Techniques for $\mathrm{Scm}$.

conductors and Scmiconductor Devices, Procecdings SPtE Vol. 794, O. H. Glcmbocki, F. H. Pollak, and J. J. Soong, cds., SPIE, Bcllingham, Washington (1987) pp. 116-120.

H. Shen, S. H. Pan, F. H. Pollak, and R. N. Sacks, Plotoreflectance and thermorcflectance of a $G a A s / G a_{10 . k}, A l_{11 \text { is }} A s$ multiple quantum well, in Spectroscopic Characterization Tecliniques for Semiconductor Tcclnology III, Procecdings SPIE Vol. 946, O. J. Glcmbocki, F. H. Pollak, and F. Ponce, cds., SPtE, Bellingliam, Washington (1988) pp. 36-42.

H. Shen, Z. Hang, F. H. Pollak, K. Capuder, and P. E. Norris, In situ monitoring of OMVPE of GaAs and $G a_{1-} A l_{1} A s$ $(x=0.17)$ by contactless photorefleclance, in Surface and interfacc Analysis of Microclectronic Matcrials Processing and Growth, Procccdings SPIE Vol. 1186, L. J. Brillson and F. It. Pollak, cds., SPIE, Bellingham, Washington (1989) pp. 27-35.

X. Yin, F. H. Pollak, J. T. Fitcl, C. Il. Bjorkman, and G. 1.ucov. sky, Photorcflectance study of strain at $\mathrm{Si} / \mathrm{SiO})_{2}$ interfaces pre pared by thermal oxidation of silicon, in Surface and luterface Analysis of Microclectronic Matcrials Processing and Grouth. Proccedings SPIE Vol. 1186, L. J. Brillson and I. II. t'ollak, cds., SPIE, Bcllingham, Washington (1989) pp. 122-130.

\section{Photoluminescence}

\subsection{Introduction}

Photoluminescence (PL) depends on the fact that electrons residing in the valence band of a scmiconductor can be excited via optical absorption to the conduction band, to an impurity, or to a defect level in the energy gap. PL can be used to determine the energy gap of a semiconductor sample. This technique is especially uscful for III-V and II-VI ternary alloys like $\mathrm{Al}_{4} \mathrm{Ga}_{1-1} \mathrm{As}$ and $\mathrm{Zn}_{1} \mathrm{Cd}_{1-1} \mathrm{Te}$, because the energy gap, which varies with the compositional parameter $x$, must be accurately known for most applications. When this process is inverted, $x$ can be found from the gap value and the known relation belween gap energy and composition. P'lotoluminescence also detects the presence of impurities and crystalline defects in semiconductors, which affect materials quality and device performance. lach impurity produces a characteristic feature or sel of features in the spectrum. Hence, the impurity type can be idenlified, and multiple impuritics can be detected in a single PL spectrum. In some cases, PL. can measure the concenlration of impurities. Comparison of PL peak halfwidths from sample to sample gives an indication of impurity concentration, carrier concentration, and crystal perfection.

\subsection{Physical Basis}

Photoluminescence results from radiative relax. alion of an oplicilly excited population. In order to ation of an oplically excied poming photon energy
cause this excitation, the incoming 
Table 5. Photoreflectance spectroscopy sensitivity. Given are sensitivities for the mcasurement of crystallinity, $x$; strcss, $\chi ;$ field strength, $F_{\mathrm{dc}}$; surface photovoltage, $V_{\mathrm{f}}$; and doping density, $N_{\mathrm{d}}$. The notations uscd for the measured quantity column are intensity, $l$; energy, $h \nu$; damping, $I$; bandgap, $E_{g}$; splitting energy, $\Delta E_{\text {split; }}$ deformation potential, $b$; compliances, $S_{11}$ and $S_{12}$; energy of Franz Keldysh oscillation lobe, $E_{m}$; oseillation number, $m$; energy difference, $E_{2}-E_{1}$; shift of critical point, $\delta E_{\mathrm{cp}}$; and spacing of Franz Keldysh oscillations, $\Delta E_{\text {Fro. }} \Delta V$ is the built-in potential minus the photovoltage of the laser minus the thermal energy

\begin{tabular}{|c|c|c|c|c|c|c|}
\hline Method & Matrix & Quantity & $\begin{array}{l}\text { Measured } \\
\text { quantity }\end{array}$ & Conversion & Sensitivity ${ }^{z}$ & $\begin{array}{l}\text { Ref. } \\
\text { (sec below) }\end{array}$ \\
\hline PR & Si & crystallinity & $I, h \nu, \Gamma$ & qualitative & & 1 \\
\hline PR & $\operatorname{In}_{x} \mathrm{Ga}_{1-x} \mathrm{As}$ & $x$ & $E_{\mathrm{g}}$ & $E_{\mathrm{g}} / \mathrm{cV}=1.425-1.337 x+0.270 x^{2}$ & $x=0$ to 0.15 & 2 \\
\hline PR & $\mathrm{GaAs} / \mathrm{Si}$ & stress & $\Delta E_{\text {split }}$ & $\Delta E_{\mathrm{split}}=2 b\left(S_{11}-S_{12}\right) \chi$ & $\chi=(150 \pm 50) \mathrm{MPa}$ & 3 \\
\hline PR & GaAs/GaAlAs & field strength & $E_{m}$ vs $m$ & $m \pi=\theta+(4 / 3)\left[\left(E_{m}-E_{0}\right) / h O\right]^{3 / 2}$ & $\begin{array}{l}F_{\mathrm{dc}}-(2 \text { to } 4) \times \\
10^{5} \mathrm{~V} / \mathrm{cm}\end{array}$ & 4 \\
\hline PR & mețal/GaAs & $\begin{array}{c}\text { surface } \\
\text { photovoltage }\end{array}$ & $E_{m}$ vs $m$ & $m \pi=0+(4 / 3)\left[\left(E_{m}-E_{0}\right) / h O\right]^{3 / 2}$ & $V_{\mathrm{F}}=(0.73 \pm 0.02) \mathrm{V}$ & 5 \\
\hline PR & GaAs & doping density & $E_{2}-E_{1}$ & $\begin{array}{c}N_{\mathrm{d}}=(\Delta V) N_{\mathrm{d}}= \\
\left(E_{2}-E_{1}\right)^{3}\left(3.46 \times 10^{20}\right) \mathrm{cm}^{-3}\end{array}$ & $\begin{array}{l}N_{\mathrm{d}}=\left(1 \times 10^{14} \text { to }\right. \\
\left.1 \times 10^{16}\right) \mathrm{cm}^{-3}\end{array}$ & 6 \\
\hline PR & GaAs & doping density & $\delta E_{\mathrm{cp}}$ & 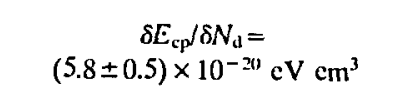 & $N_{\mathrm{d}}>1 \times 10^{16} \mathrm{~cm}^{-3}$ & 7 \\
\hline PR & GaAs & doping density & $\Delta E_{\mathrm{FKO}}$ & $\Delta E_{\mathrm{FKO}}=$ const. $\times N_{\mathrm{d}}^{1 / 3}$ & $\begin{array}{l}N_{\mathrm{d}}=\left(6 \times 10^{17} \text { to }\right. \\
\left.3 \times 10^{1 \mathrm{~s}}\right) \mathrm{cm}^{-3}\end{array}$ & 8 \\
\hline
\end{tabular}

-Values quoted in references below.

References

[1] A. Giordana, R. Glosser, K. Joyner, and G. Pollack, J. Electronic Mat. 20, 949 (1991).

[2] R. E. Nahory, M. A. Pollack, and J. C. DeWinter, J. Appl. Phys. 46, 775 (1975).
[3] A. Dimoulas, P. Tzanetakis, A. Georgakilas, O. J. Glembocki, and A. Christou, J. Appl. Phys. 67, 4389 (1990); T. Kanata, H.

Suzawa, M. Matsunaga, H. Takakura, Y. Hamakawa, H. Kato, and T. Nishino, Phys. Rev. B41, 2936 (1990).
[4] X. Yin, F. H. Pollak, L. Pawlowicz, T. O'Neill, and M. Hafizi, Appl. Phys. Lett

Wright, R. W. Kaliski, and D. A. Williams, J. Crystal Growt, Appl. Phys. Lett. 56, 1278 (1990); N. Bottka, D. K. Gaskill, P. D.

[5] X. Yin, H-M. Chen, F. P. A. Williams, J. Crystal Growth 107, 893 (1991). $260(1991)$.

[6] M. Sydor, J. Angelo, W. Mitehel, T. W. Haas, and M-Y. Yen, J. Appl. Phys. 66, 156 (1989).

[8] W. M. Dunean and A. F. Schreiner, Solid W. M. Theis, J. Appl. Phys. 62, 4558 (1987).

[8] W. M. Duncan and A. F. Schreiner, Solid State Commun. 31, 457 (1979). 
must equal or exceed the energy difference between the initial and final states of the electron. Such an excited electron usually returns to its initial state after a short time. If the excited electron returns to its initial state by radiative means, the process emits a photon whose energy is the difference between the excited and the initial state energies. The spectral distribution of the emitted photons shows an emission peak at the energy (or wavelength) corresponding to each excited level.

Photoluminescence is complicated by the behavior of the electron during its excited period. The excited electron leaves behind it a deficiency in the valence band, a mobile hole. The Coulomb attraction between the excited electron and the hole can bind the two particles into a system called a free exciton, much as a proton and an electron form a bound hydrogen atom. The exciton can move as a unit through the crystal, but carries no current because its net charge is zero. From this perspective, the return of the electron to its initial state can be viewed as the collapse of the temporary excitonic state, when the electron recombines with the hole.

The exciton influences the PL spectrum in several ways. Because it is a bound state, the excited state energy is slightly less than the bandgap energy, generally by a few meV. Hence, for PL near the energy gap, the equation for the energy of the emitted photon is

$$
\hbar \omega=E_{\mathrm{g}}-E_{\mathrm{cx}},
$$

where $E_{\mathrm{ex}}$ is the binding energy of the excitonic state. This equation applies for a direct energy gap semiconductor. For an indirect gap semiconductor, a phonon must also be involved to properly conserve momentum. Then the equation for the emitted photon energy is ( $E_{\mathrm{ph}}$ is the photon energy)

$$
\hbar \omega=E_{\mathrm{g}}-E_{\mathrm{ex}}-E_{\mathrm{ph}} .
$$

However, this free exciton recombination dominates only when the sample is very pure. When donor, acceptor, or neutral impurities are present, free excitons respond to the Coloumb fields of these defects to form bound excitons. Each type of exciton produces a PL peak when recombination occurs, and each can be identified in the spectrum.

\subsection{Experimental and Technical Details}

Figure 16 shows the main elements of a standard PL arrangement. Any of several commercially available types of laser may be used, provided that the

energy of the laser's photons exceeds the energy gap of the material, and the laser power is adequate to excite a usable PL signal. An argon ion laser is suitable for many semiconductors of technological interest such as $\mathrm{Si}(1.12 \mathrm{eV}), \mathrm{Al}_{x} \mathrm{Ga}_{1-x} \mathrm{As}(1.42 \mathrm{eV}$ to $2.16 \mathrm{eV}$ ) and $\mathrm{Zn}_{x} \mathrm{Cd}_{1-x} \mathrm{Te}$. Laser powers $\leq 50 \mathrm{~mW}$ are usually adequate, but power densities must be minimized to avoid sample hcating effects. It is generally possible to avoid heating and still obtain adequate signal to noise by defocusing the laser or reducing the incident laser power.

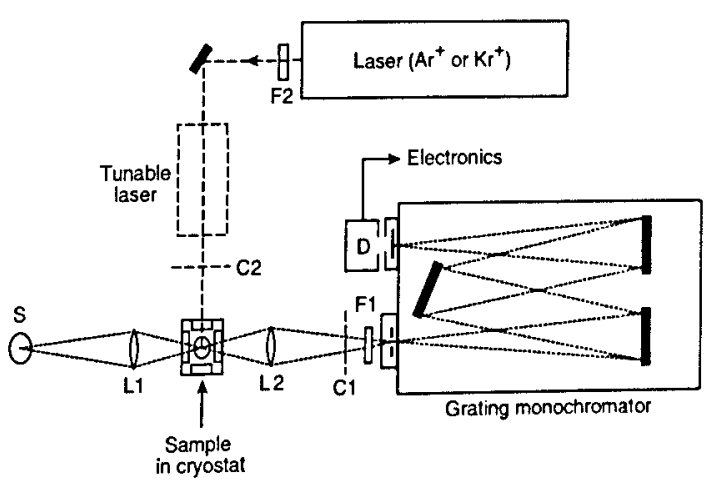

Fig. 16. Schematic diagram of a photoluminesecnec arrangement, showing the exciting $\mathrm{Ar}^{+}$or $\mathrm{Kr}^{+}$laser, filter $\mathrm{F} 2$ to block unwanted laser lines, the sample mounted in a eryostat, Icns L2 to bring the PL. radiation to the monochromator entrance slit, chopping whecl $\mathrm{C} 1$ to modulatc the light for lock-in detcetion, filter FI to exelude the lascr line from the monochromator, the grating monochromator itself, and detcctor D followed by appro. priate clectronies to process and analyze the signal. The tunable dye laser and chopping wheel $\mathrm{C2}$ shown in dashed outline arc auxiliary cquipment for lumincsecnce exeitation measurements, a rclated tcchniquc. Lamp $S$ and lens Ll allow auxiliary absorp. tion spectroseopy, using the same monochromator and detector. (Scc Sce. 6.5, General Refs., Lightowlers (1990), fig. 4, p. 138.)

The sample's PL radiation passes through a monochromator and then to a detector, to yicld the spectral distribution of intensity versus wavelength or energy. A standard photomultiplier tube is usually employed for visible and near visible applica. tions. Quantum detectors such as germanium and InAs photodiodes are employed for the near infrared. All of these give the best signal-to-noisc ratio when cooled to temperatures as low as $77 \mathrm{~K}$ for solid-state photodiodes. Improvement in sensitivity comes with the use of an optical muli-channel analyzer such a Si pholodiode array. The array has the advantage of providing complete spectra in a short time.

In spectral regions where signal to noise is detecIn spectral regions where
tor limited, decided improvements in sensilivity and 
decreases in measurement times come if the grating monochromator in Fig. 16 is replaced by an Michelson interferometer to carry out Fourier transform spectroscopy. This instrument has already been discussed in the section on infrared spectroscopy.

It is usually necessary to cool the sample below room temperature to observe the best PL spectra. Cooling reduces the thermal broadening of the excited carrier spectrum of the order $k_{\mathrm{B}} T$, and also reduces the importance of nonradiative de-excitation processes. Cooling to liquid nitrogen temperature is often adequate. The sample can be mounted to a cold finger connected to a liquid nitrogen dewar, and can be held to within a few degrees of $77 \mathrm{~K}$.

When necessary, cooling to liquid helium temperatures can be conveniently obtained by a continuous-flow liquid helium system. With proper shielding and an adequate flow rate of helium (typically $1 \mathrm{~L} / \mathrm{h}$ to $3 \mathrm{~L} / \mathrm{h}$ ), sample temperatures as low as $6 \mathrm{~K}$ to $10 \mathrm{~K}$ can be maintained. Temperatures down to $-10 \mathrm{~K}$ can be reached by mechanical refrigerators. If necessary, temperatures to $4 \mathrm{~K}$ can be obtained by immersion in liquid helium or to $2 \mathrm{~K}$ by pumped helium methods.

\subsection{Illustrative Applications}

Figure 17 shows how specific impurities in a semiconductor such as silicon clearly appear in PL

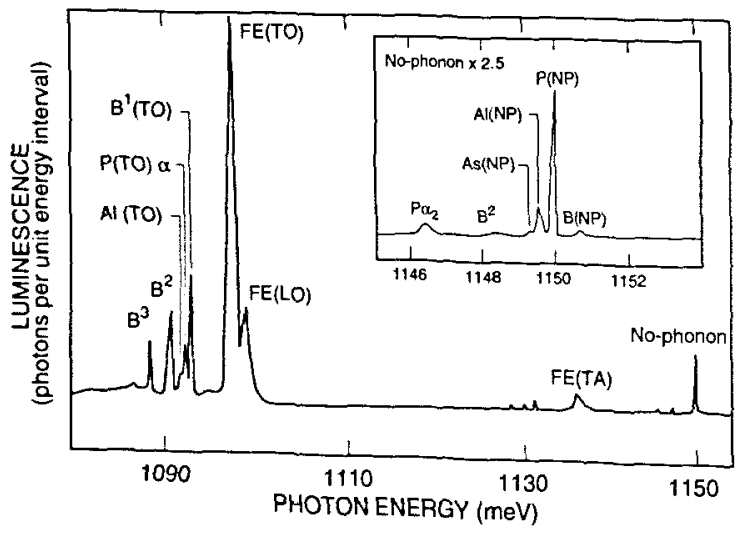

Fig. 17. PL spectrum of high-resistivity $(>20 \mathrm{k} \Omega \mathrm{cm})$ near-intrinsic silicon showing the presence of the following impurities and their eoncentrations, in units of $10^{12} \mathrm{~cm}^{-3}: \mathrm{B}, 1.36 ; \mathrm{P}, 1.69$; $\mathrm{Al}, 0.61$; and $\mathrm{As}, 0.14$. The fingerprint features for each element are marked. Free-exciton lines are marked FE. Bccause silicon is an indirect-gap scmiconductor, phonon modes must be in volved in FE transitions. They are indicated as TO (transverse optical), LO (longitudinal optical), and TA (transverse acoust ic) Peaks labeled NP (no phonon) come from bound excitons, whicl do not require phonon assistance. The technique for derivin quantitative impurity concentration data from such spectra is discusscd in the caption for Fig. 18. (See Sec. 6.5, General Refs. Lightowlers (1990), fig. 9, p. 144.) spectra. The caption explains the source of each peak. Figure 18 illustrates the conversion of $\mathrm{PL}$ data into accurate values for impurity concentrations. Figure 19 shows how two-dimensional PL mapping can help evaluate the homogeneity and quality of a semiconductor wafer, in this case an epitaxial layer of InGaAsP grown on InP. The technique uses the fact that each parameter that describes a PL peak can be related to a sample property. The peak position, for instance, gives the energy gap value, which for an alloy like InGaAsP varies with the proportions of the component elements. Hence, a map of peak PL wavelength correlates well with a map of composition.

Table 6 presents the sensitivities of typical quantities measured by photoluminescence such as composition in III-V and II-VI alloys and the concentration of $\mathrm{B}, \mathrm{P}, \mathrm{As}$, and $\mathrm{Al}$ in $\mathrm{Si}$. The reader should refer to the citations in the table for more specific details.

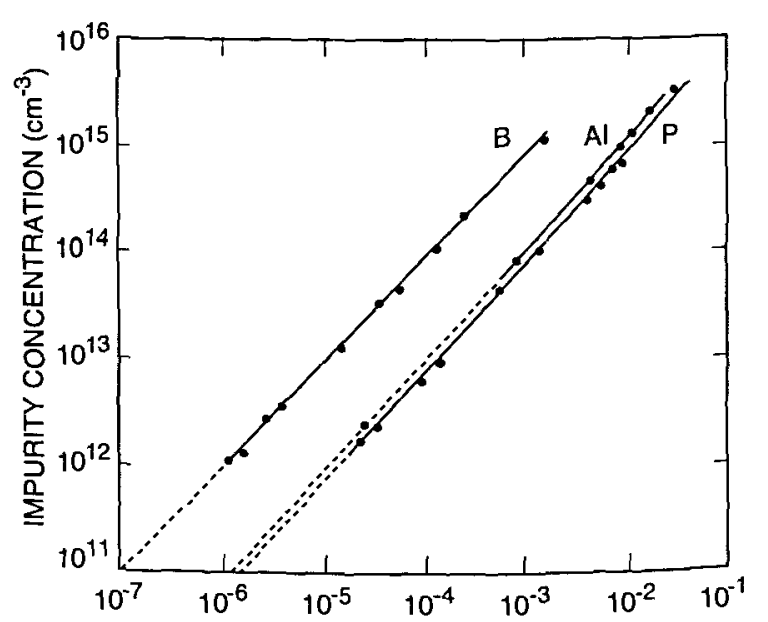

NP LINE-AREA DIVIDED BY FE PEAK-HEIGHT RATIO (eV)

Fig. 18. Calibration charl to convert PL information like that in Fig. 17 into impurity concentration for $B, A l$, and $P$ in silicon. It is difficult to establish absolute intensity standards for PL, because of differences in laser excitation power and focusing, $t \mathrm{~cm}$ perature, and other factors. This chart uses a calibration method which is internal to a given spectrum, and hence avoids many of the problems of absolute calibration, although it was established using careful independent measurements of coneentrations, and of temperature and light intensity. The area of the NP peak for the particular impurity is ratioed against the height of the FE(TO) peak in the same spectrum. More recent work has cxtended the upper limit of the calibration curves to about $10^{17}$ $\mathrm{cm}^{-3}$. (See See. 6.5, General Refs., Lightowlers (1990), fig. 14, p. 148.) 
Table 6. Photoluminescence sensitivity. Given are sensitivitics for the mcasurement of suhstitutional boron, [B,]; phosplorus, [P.]; arsenic, [As, ]; and aluminum, [Al $\mathrm{A}_{\mathrm{s}}$, in crystalline Si. Sensitivitics for determination of ternary composition, $x$, are given for $\mathrm{Al}_{4} \mathrm{Ga} \mathrm{a}_{1}, \mathrm{As}$, $\mathrm{In}_{x} \mathrm{Ga}_{1-x} \mathrm{As}$, and $\mathrm{Zn}_{x} \mathrm{Cd}_{1_{-x}}$ Te. The notations used for the measured quantity column are the boron transverse optical hl multicxeiton peak intensity, $I\left(\mathrm{~B}_{\mathrm{To}} \mathrm{b} 1\right)$; free exciton intensity, $J(\mathrm{FE})$; phosphorus no-phonon peak illtensity, $I\left(\mathrm{P}_{\mathrm{N} 1}\right)$; arsenic no-phonon peak intensity, $I\left(\mathrm{As}_{\mathrm{NP}}\right)$; aluminum no-phonon peak intensity, $I\left(\mathrm{As}_{\mathrm{N} \mathrm{P}}\right)$; and energy, $h \nu$

\begin{tabular}{|c|c|c|c|c|c|c|}
\hline Method & Matrix & Quantity & $\begin{array}{l}\text { Mcasured } \\
\text { quantity }\end{array}$ & Conversion & Sensitivity" & $\begin{array}{c}\text { Ref. } \\
\text { (sec helow) }\end{array}$ \\
\hline $\begin{array}{l}\text { Exciton } \\
\text { intensity } \\
\text { ratio }\end{array}$ & $\mathrm{Si}$ & {$\left[B_{s}\right]$} & $\begin{array}{l}I\left(\mathrm{~B}_{\mathrm{To}} \mathrm{b} 1\right) / /(\mathrm{FE}) \\
@ 4.2 \mathrm{~K}\end{array}$ & $\begin{array}{c}\log \left[\mathrm{B}_{\mathrm{s}} / \mathrm{cm}^{3}\right]= \\
1.435 \log \left[/_{\mathrm{B}} / /_{\mathrm{FE}}\right]+12.81\end{array}$ & $\pm 2 \times 10^{111} \mathrm{~cm}^{-3}$ & 1 \\
\hline $\begin{array}{l}\text { Exciton } \\
\text { intensity } \\
\text { ratio }\end{array}$ & $\mathrm{Si}$ & {$\left[P_{s}\right]$} & $\begin{array}{l}I\left(\mathrm{P}_{\mathrm{NP}}\right) / I(\mathrm{FE}) \\
@ 4.2 \mathrm{~K}\end{array}$ & $\begin{array}{c}\log \left[\mathrm{P} / \mathrm{cm}^{3}\right]= \\
1.280 \log \left[h_{\mathrm{p}} / /_{\mathrm{FE}}\right]+12.79\end{array}$ & $\pm 4 \times 10^{111} \mathrm{~cm}^{-3}$ & 1 \\
\hline $\begin{array}{l}\text { Exciton } \\
\text { intensity } \\
\text { ratio }\end{array}$ & $\mathrm{Si}$ & {$\left[\mathrm{As}_{\mathrm{s}}\right]$} & $\begin{array}{l}I\left(\mathrm{As}_{\mathrm{NP}}\right) /(\mathrm{FE}) \\
@ 4.2 \mathrm{~K}\end{array}$ & $\begin{array}{c}\log \left[\mathrm{As}_{s} / \mathrm{cm}^{3}\right]= \\
1.049 \log \left[I_{\mathrm{AN}} / I_{\mathrm{rt}}\right]+12.76\end{array}$ & $\pm 1 \times 10^{11} \mathrm{~cm}^{-3}$ & 1 \\
\hline $\begin{array}{l}\text { Exciton } \\
\text { intensity } \\
\text { ratio }\end{array}$ & $\mathrm{Si}$ & {$\left[\mathrm{Al}_{\mathrm{s}}\right]$} & $\begin{array}{l}I\left(\mathrm{Al}_{\mathrm{NP}}\right) / I(\mathrm{FE}) \\
@ 4.2 \mathrm{~K}\end{array}$ & $\begin{array}{c}\log \left[\mathrm{Al} / / \mathrm{cm}^{3}\right]= \\
1.359 \log \left[I_{\mathrm{Al}} / I_{\mathrm{FE}}\right]+1.3 .19\end{array}$ & $\pm 8 \times 10^{111} \mathrm{~cm}^{-1}$ & 1 \\
\hline Peak energy & $A l_{x} \mathrm{Ga}_{l_{-x}} \mathrm{As}$ & $x$ & $\begin{array}{l}h \nu \\
@ 300 \mathrm{~K}\end{array}$ & $\begin{array}{c}h \nu / \mathrm{eV}=1.424+1.247 x \\
(0<x<0.45)\end{array}$ & $\pm 0.002 x$ & 2 \\
\hline Peak energy & $\mathrm{In}_{x} \mathrm{Ga}_{\perp-x} \mathrm{As}$ & $x$ & $\begin{array}{c}h \nu \\
@ 300 \mathrm{~K}\end{array}$ & $h \nu / \mathrm{cV}=1.424-1.337 x+0.270 x^{2}$ & $\pm 0.002 x$ & 3 \\
\hline Peak energy & $\mathrm{Zn}_{x} \mathrm{Cd}_{1-x} \mathrm{Te}$ & $x$ & $\begin{array}{c}h \nu \\
(1 i 4.2 \mathrm{~K}\end{array}$ & $h \nu / \mathrm{cV}=1.605+0.505 x+0.28 .5 x^{2}$ & $\pm 0.0002 x$ & 4 \\
\hline
\end{tabular}

- Calculated as the concentration-equivalent-of-noisc assuming \pm 0.02 signal-to-noisc ratio for intensity measurements and $\pm 2 \mathrm{meV}$ and $\pm 0.2 \mathrm{meV}$ energy precision at room temperature and $4.2 \mathrm{~K}$, respectively.

\section{References}

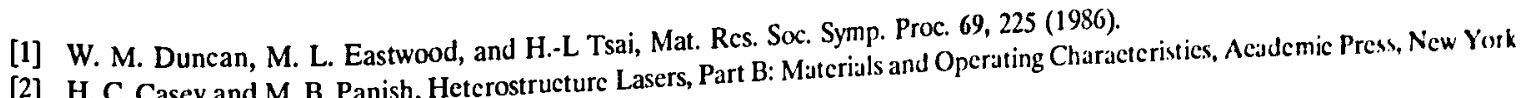

(1978), p. 16.
[3] R. E. Nabory, M. A. Pollack, and J. D. DeWinter, J. Appl. Phys. 46, 775 (1975).
[4] N. Ses. Soc. Symp. Proc. 90, 455 (1987): W. M.

[4] N. Magnea, F. Dal'bo, J. L. Pautrat, A. Million, L. Dieioccio, and G. Feuiller. Res. Soc. Symp. Proc. 161, $39(199 \%)$.

Duncan, R. J. Koestner, J. H. Tregilgas, H.-Y. Liu, and M.-C. Chen, Mar. Res Soc. Symp. Proc. 161, 3y (19) 


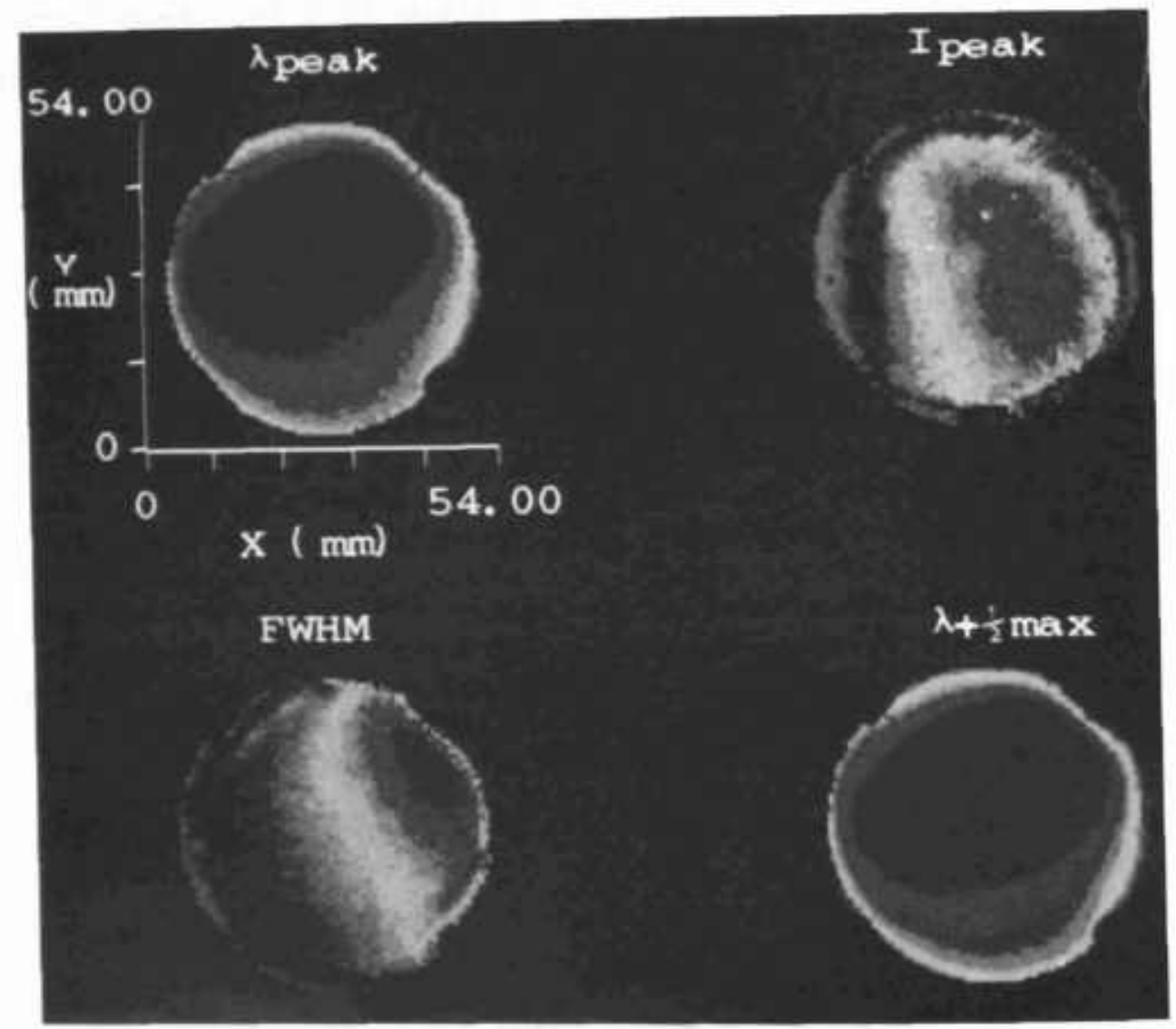

Fig. 19. Two-dimensional maps of PL parameters from a $50 \mathrm{~mm}$ wafer of cpitaxial InGaAsP grown on InP, obtained using a commercial system with $x-y$ scanning capability. Upper left, wavelength of the PL peak, which is related to sample composition; upper right, peak intensity, related to defect density; lower left, peak full width at half maximum (FWHM), related to closeness of the lattice match between layer and substrate; lower right, upper wavelength at which PL intensity falls to $50 \%$ of the peak value, related to sample composition. Spatial variations in all the parameters are clearly seen. (Sec Sec. 6.5, Applications Refs., Henncssy, Miner, and Moore (1990), fig. 3.)

\subsection{References}

\section{General}

P. Goldberg, Luminescence of Inorganic Solids, Academic, New York (1966).

E. C. Lightowlers, Photoluminescence characterisation, in Growth and Characterization of Semiconductors, R. A. Stradling and P. C. Klipstein, eds., Adam Hilger, Bristol (1990) pp. 135163.

D. K. Schroder, Semiconductor Material and Device Characterization, John Wiley, New York (1990) pp. 490-494.

M. L. W. Thewalt, M. K. Nissen, D. J. S. Beckett, and K. R. Lundgren. High performance photoluminescence spectroscopy using Fourier transform interferometry, in Impurities, Defects and Diffusion in Scmiconductors: Bulk and Laycred Structures, Materials Research Society Symposia Proceedings Vol. I63, D. J. Wolford, J. Bernhole, and E. E. Haller, eds., Materials Research Society, Pittsburgh, Pennsylvania (1989) pp. 221-232.

\section{Applications}

K. K. Bajaj and D. C. Reynolds, An overview of optical characterization of semiconductor structures and alloys, in Modern Optical Characterization Techniques for Semiconductors and Semiconductor Devices, SPIE Procecdings Vol. 794, O. J. Glembocki, F. H. Pollak, and J. J. Song, eds., SPIE, Bellingham, Washington (1987) pp. 2-10.

S. G. Bishop, Characterization of semiconductors by photoluminescence and photoluminescence excitation spectroscopy, in Optical Characterization Techniques for Scmiconductor Technology, SPIE Proceedings Vol. 276, D. E. Aspnes, S. So, and R. F. Potter, cds., SPIE, Bellingham, Washington (1981) pp. 2-I0.

M. Bugajuski, K. Nauka, S. S. Rosner, and D. Mars, Photoluminescence studics of anncaled GaAs films grown on Si substrates, in Heteroepitaxy on Silicon: Fundamentals, Structure, and Devices, Materials Research Socicty Symposia Procecdings Vol. 116, H. K. Choi, R. Hull, H. Ishiwara, and R. J. Nemanich, eds., Matcrials Research Socicty, Pittsburgh, Pennsylvania (1988) pp. 233-238. 
Y.H. Chen and S. A. Lyon, Photoluminescence and diffusivity of free excitons in doped silicon, IEEE J. Quantum Electron. QE. 25, 1053-1055 (1989).

H. Conzelmann, Photoluminescence of transition metal complexes in silicon, Appl. Phys. A 42, 1-18 (1987).

W. M. Duncan, M. L. Eastwood, and H-L. Tsai, Fourier transform photoluminescence analysis of trace impurities and defects in silicon, in Materials Characterization, Materials Research Society Symposia Proceedings Vol. 69, N. Chcung and M.-A. Nicolet, eds., Materials Research Society, Pittsburgh, Pennsylvania (1986) pp. 225-230.

J. A. Fouquet, R. R. Saxena, and G. A. Patterson, Near-infrared photoluminescence of high-resistivity epitaxial GaAs and InP and of epitaxial GaAs on Si, IEEE J. Quantum Elcctron. QE-25, 1025-1034 (1989).

A. Freundlich, G. Neu, A. Leycuras, R. Carles, and C. Verie, Heterogeneous strain relaxation in GaAs on $\mathrm{Si}$ (100), in Heteroepitaxy on Silicon: Fundamentals, Structure, and Devices, Materials Research Society Symposia Procecdings Vol. 116, H. K. Choi, R. Hull, H. Ishiwara, and R. J. Nemanich, eds., Materials Research Socjety, Pittsburgh, Pennsylvania (1988) pp. 251256.

J. Hennessy, C. Miner, and C. Moore, Photoluminescence mapping in inspection and process control, Photonics Spectra 24, 91-96 (1990).

E. D. Jones and L. R. Dawson, Photoluminescence studies of 1nGaAlAs quaternary alloys, in Spectroscopic Characterization Techniques for Semiconductor Technology I1I, Proccedings SPIE Vol. 946, O. J. Glembocki, F. H. Pollak, and F. Ponce, cds., SPIE, Bellingham, Washington (1988) pp. 172-176.

E. S. Koteles, Y. Y. Chi, and R. F. Holmstrom, Low temperature photoluminescence signature of a two-dimensional electron gas, in Modern Optical Characterization Techniques for Semiconductors and Semiconductor Devices, Procecdings SPIE Vol. 794. O. J. Glembocki, F. H. Pollak, and J. J. Song, eds., SPIE, Bellingham, Washington (1987) pp. 61-65.

H. P. Lee, Y-H. Huang, X. Liu, J. S. Smith, E. R. Weber, P. Yu, S. Wang, and Z. Lilicnthal-Weber, The photoluminescence and TEM studies of patterned GaAs films on Si substrates grown by molecular beam epitaxy, in Heteroepitaxy on Silicon: Fundamentals, Structure, and Devices, Materials Research Society Symposia Proceedings Vol. 116, H. K. Choi, R. Hull, H. Ishiwara, and R. J. Ncmanich, cds., Materials Research Socicty, Pittsburgh, Pennsylvania (1988) pp. 219-226.

C. J. Miner, Non-destructive, wholc wafer assessment of optoelectronic epitaxial materials, Semicond. Sci. Tcchnol. 7, A10-A15 (1992).

C. J. L. Moore and C. J. Miner, A spatially resolved spectrally resolved photoluminescence mapping system, J. Crystal Growth 103, 21-27 (1990).

A. L. Moretti, F. A. Chambers, G. P. Devane, and F. A. Kish, Characterization of $\mathrm{GaAs} / \mathrm{Al}_{x} \mathrm{Ga}_{1-x}$ As structures using scanning photoluminescence, IEEE J. Quantum Electron. QE-25, 10181024 (1989).

R. J. Nemanich, D. K. Bicgelsen, R. A. Strect, B. Downs, B. S. Krusor, and R. D. Yingling, Strain in graded thickness GaAs/Si hetcrocpitaxial structures grown with a buffer laycr, in IIct. eroepitaxy on Silicon: Fundamentals, Structure, and Devices, Matcrials Research Socicty Symposia Proceedings Vol. 116, 11 . K. Choi, R. Hull, H. Ishiwara, and R. J. Nemanich, eds., Matcrials Research Socicty, Pittsburgh, Pennsylvania (1988) pp. 245250 .

T. Nishino, H. Nakayama, J. Katsu ra, and Y. I tamakawa, Photolumincscence characterization of thermally induced defects in Czochralski-grown Si wafers, Optical Characterization Techniques for Semiconductor Technology, Proceedings SPIE Vol. 276, D. E. Aspnes, S. So, and R. F. Potter, eds., SPIE, Bellingham, Washington (I98I) pp. 31-38.

T. Nishino, A new high-sensitivity charactcrization method of interface stress at hetcrostructures by Cr-related lumincsecnce. IEEE J. Quantum Electron. QE-25, 1046-1052 (1989).

J. E. Potts, T. L. Smith, and H. Cheng, Photolumineseence studics of donors in molecular beam cpitaxy (MBE) grown $\mathrm{ZnSc}$, in Modern Optical Characterization Techniques for Semiconductors and Semiconductor Devices, Procecdings SPIE Vol. 794, $O$. J. Glembocki, F. II. Pollak, and J. J. Song, cds., SPIE, Bellingham, Washington (1987) pp. 27-33.

D. C. Reynolds and C. W. Litton, Semiconductor matcrials characterization by high-resolution optical spectroscopy, in Optical Characterization Techniques for Semiconductor Technology, Proceedings SPIE Vol. 276, D. E. Aspnes, S. So, and R. F. Portter, cds., SPIE. Bellingham. Washington (1981) pp. 11-3).

E. K. Ricmer, T. G. Stocbe, and A. A. Khan, Scanning photoluminescence, in Modern Optical Characterization Techniques for Semiconductors and Semiconductor Devices, Procecdings SP'lE Vol. 794, O. J. Glembocki, F. H. Pollak, and J. J. Song eds, SPIE, Bellingham, Washington (1987) pp. 20-26.

B. J. Skromme, R. Bhat, H. M. Cox, and E. Colas, Identification of donors in GaAs by resonantly excited high-ficld magneterpectroscopy, IEEE J. Quantum Electron. QE-25, 1035-10145 (1 989)

M. L. W. Thewalt and D. M. Brake, Ulera-high resolution photoluminescence studies of bound cxcitons and multi-bound cxciton complexes in silicon, Matcrials Science Forum Vols. $65 .(6,(199)$ 187-198.

B. A. Wilson, Novel applications of optical techniques to the study of buricd semiconductor interfices. IEEE J. Ouantum Elcctron. QE-25. 1012-1017 (1989).

S. Zcmon, C. Jagannath, S. K. Shasury, W. J. Miniscalco, and G. Lambert, Resonant photoluminesence excitation of annesicd GaAs films grown on Si substrates, in Hetcrocpitaxy on Silicon: Fundamentals, Structurc, and Devices, Matcrials Research Sici. cty Symposia Procecdings Vol. 116, II. K. Choi, R. Ilull, II. J thi and R. J. Nomanich, eds., Matcrials Research Soxicty, Pittsburgh, Pennsylvania (1988) pp. 239-245. 


\section{Raman Scattering}

\subsection{Introduction}

Raman scattering results when photons interact with optical lattice vibrations (phonons) of a semiconductor crystal lattice. The way in which these phonons appear in a Raman spectrum depends on the crystallinity of a sample and on its crystal orientation. Hence, Raman scattering can determine whether a sample is amorphous or crystalline, and whether the crystal is of good quality or is altered by damage or imperfections. The method is also sensitive to strain effects, which change semiconductor lattice structure and hence phonon frequencies. Since phonon frequencies and amplitudes in an alloy semiconductor like $\mathrm{Al}_{x} \mathrm{Ga}_{1-x}$ As change with the degree of alloying, Raman scattering can be used to measure composition as well. By changing the wavelength of the light exciting the scattering, the penetration depth can be changed, which gives the capability to probe layered or inhomogeneous structures.

In microprobe Raman scattering, a microscope is coupled to the Raman system, making it possible to probe regions as small as $-1 \mu \mathrm{m}$ across. This allows for the identification of contaminating impurities in extremely small regions of the specimen. In resonance Raman scattering, the scattering process is strengthened when the incoming photon energy matches the energy gap or other higher-order critical point energies in the sample's band structure. This resonance strengthens the inherently weak Raman process and also gives band structure information as well as phonon information.

\subsection{Physical Basis}

Raman scattering, a two-photon process, is more complex than one-photon optical processes such as photoluminescence. If light impinges on the surface of a semiconductor, a large portion is reflected, transmitted, absorbed, or elastically scattered (Rayleigh scattering), with no change in frequency. A small part of the light interacts inelastically with phonon modes, so that the outgoing photons have frequencies shifted from the incoming values. These are the Raman-scattered photons. Since the photons can either gain energy or lose energy in their phonon interactions, the scattered light can be of higher frequency (anti-Stokes-shifted) or of lower frequency (Stokes-shifted) than the incident light. Because of statistical considerations, the Stokes modes are stronger and are usually the ones observed in Raman measurements at room temperature.
The up-shifted and down-shifted photons can be treated as side bands of the exciting light that come from the nonlinear interaction between the light and the material. This can be seen by examining the crystal polarization $P$ due to the phonons, which is given by

$$
P=\alpha E
$$

where $E$ is the applied electric field $E_{0} \cos \omega t$ and the polarizability $\alpha$ is given by

$$
\alpha=\alpha_{1} u+\alpha_{2} u^{2}+\alpha_{3} u^{3}+\ldots,
$$

where $u$ is the phonon displacement, and $\alpha_{1}, \alpha_{2}, \ldots$ are constants. The first term in Eq. (20) is the dipole approximation, and the other terms represent more complex anharmonic contributions. If the phonon vibrates at frequency $\Omega, u$ is of the form $u=u_{0} \cos (\Omega t)$ and Eq. (19) becomes

$$
\begin{gathered}
P=E_{0}\left[\alpha_{1} u_{0} \cos (\omega t) \cos (\Omega t)+\right. \\
\left.\alpha_{2} u_{0}^{2} \cos (\omega t) \cos ^{2}(\Omega t)+\ldots\right]
\end{gathered}
$$

From standard trigonometric identities, Eq. (21) can be rewritten as expressions that contain $\cos (\omega+\Omega) t, \cos (\omega \pm 2 \Omega) t \ldots, \cos (\omega+n \Omega) t$. The leading term $\cos (\omega \pm \Omega) t$ represents the fundamental Raman-shifted bands at frequency $\omega+\Omega$ (socalled anti-Stokes lines) and $\omega-\Omega$ (Stokes lines), and the others represent the interaction of the photon with multiple phonons $(n=2,3, \ldots)$.

This simple development of the theory gives the shift in photon frequency, that is, where the Raman bands lie relative to the exciting wavelength. However, the intensity and line shape of the Raman bands are more difficult to calculate. Although some appropriate theory exists, it is not easy to apply to specific semiconductors. In general, Raman scattering is a weak process, and the higher order terms in Eq. (20) generally contribute weakly. Beyond these qualitative trends, line-shape analysis of Raman spectra of semiconductors is not well developed. However, it is true that smaller half-widths correlate with higher levels of sample crystalline perfection.

When carried out in detail, the calculation of the Raman intensity depends strongly on the orientation and polarization of the exciting light relative to the crystal axes, since such geometric considerations determine how the field and the polarization interact. Hence, the Raman spectrum from a given crystal depends on its orientation, with various "allowed" and "forbidden" Raman modes for different orientations. 
An exception to the statement that Raman scattering is weak occurs in resonant Raman scattering. If the energy of the exciting photon is chosen to match a fundamental feature in the semiconductor band structure, such as the energy gap or higher order critical points in the band structure, the amount of energy imparted to the lattice increases dramatically, and so does the strength of the Raman modes.

\subsection{Experimental and Technical Details}

The overriding consideration in Raman scattering is the weakness of the signal, and the difficulty of separating it from unavoidable accompanying spectral information. Weak Raman peaks usually must be measured in the immediate neighborhood of intense Rayleigh scattering, which occurs at the energy of the exciting photon. Raman measurements require the strongest possible light sources that will not damage the sample, special optical methods to filter out the Rayleigh peak, and sensitive detection schemes to capture the few emerging Raman-shifted photons.

Any monochromatic light source can act as a Raman source. Most often, lasers operating at visible frequencies are employed to provide the necessary power. To give flexibility in varying the penetration depth, and some capability to excite resonance Raman scattering, it is better to use lasers that can be tuned over several powerful lines in the visible. Argon-ion and krypton-ion lasers are good choices; they are powerful, commercially available, and easily tunable, one from the ultraviolet to the green, the other toward the red end of the spectrum. For maximum flexibility in tuning, say for exact resonant coincidence, a tunable dye laser is the best choice. With the range of available dyes, these lasers can be tuned through the energy gaps of most semiconductors. The power is much lower than that of ion lasers but the increased signal due to the resonant effect more than compensates for this.

The optical arrangement for Raman spectroscopy is similar to that for photoluminescence (fig. 16), but with one important exception: a single monochromator is usually inadequate to separate the Raman signal from the strong accompanying Rayleigh light. A double monochromator is standard, consisting of two tandem gratings turning together and sequentially dispersing the light. In recent years, holographic notch filters have matured sufficiently that they can be used to eliminate the Rayleigh signal and allow the use of a single monochromator. Triple monochromators are sometimes used.
Raman scattering excited in the visible or ultraviolet can be detected by visible or ultraviolet detectors, so photomultiplier tubes (PMT) and array detectors work well. The PMTs should be chosen to give broad spectral coverage and to display a low dark count for maximum sensitivity. Cooled operation to reduce dark count is also important. As in photoluminescence work, it is possible to use Fourier methods to enhance Raman sensitivity or to reduce data collection time.

\subsection{Illustrative Applications}

The sensitivity of Raman scattering to phonon modes makes it possible to distinguish between amorphous and crystalline semiconductors. Figure 20 illustrates the direct way in which Raman spectra follow the increasing presence of crystalline silicon, as annealing proceeds on amorphous material.

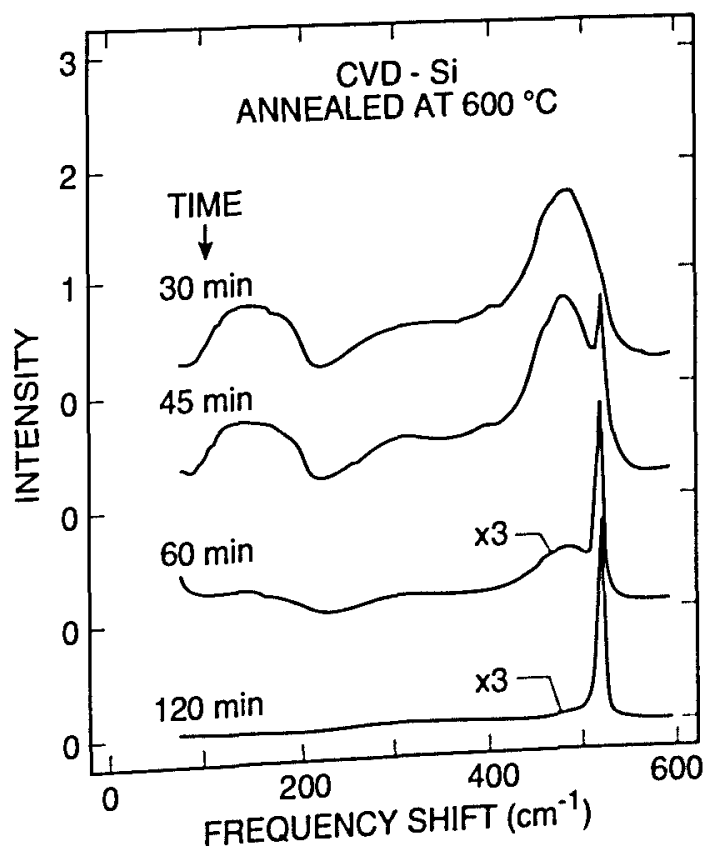

Fig. 20. Raman spectra of silicon grown by chemical sapor $\mathrm{dc}$ howing change in the character of the silicon after anposition, showing change in the ehen after $30 \mathrm{~min}$ of annealing, is nealing. The top spectum, taken after 3) min of ann only broad virtually the same as from as-grown material. After anncaling for 45 peaks coming from amorphous $520 \mathrm{~cm}^{-1}$, which comes from the min, a sharp line appears at $520 \mathrm{~cm}^{-}$, which cilicon. The hroad optical phonon characteristic of cristine sing time, until after structure continues to decrease with an little or no amorphous sili$120 \mathrm{~min}$, the spectrum indieates that little or nemanich (1986), fig. con remains. (Sec Sec. 7.5, General Refs., Nemanich (1986), 1. p. 26.) 
Figure 21 shows how strain in a semiconductor appears in a Raman spectrum. The Raman peak for epitaxial GaAs grown on a silicon substrate shifts relative to that for bulk GaAs, because the epilayer lattice spacing changes under the strain induced by the mismatch between film and substrate. Microprobe Raman analysis can be helpful for examining contamination by small particles or for examining thin films, as illustrated in Fig. 22.

Table 7 gives the sensitivities of typical quantities measured by Raman spectroscopy such as stress, impurity concentrations of $\mathrm{C}$ and $\mathrm{Zn}$ in GaAs, alloy composition, and temperature. For more specific details, the reader should refer to the citations in the table.

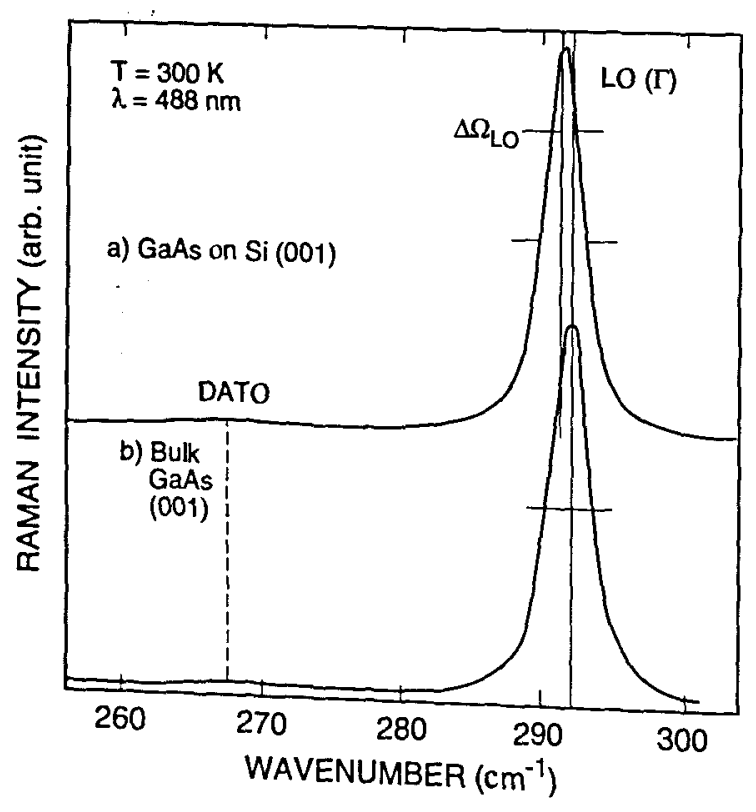

Fig. 21. Raman speetra of bulk (100) GaAs (lower curve) compared to that from a GaAs film $2 \mu \mathrm{m}$ thick grown on (100) silicon (upper curve). The main peak near $292 \mathrm{~cm}^{-1}$ comes from the longitudinal optical (LO) phonon. Peak halfwidths are the same in both curves, indicating similar sample quality. The barely visible disorder-activated transverse optical (DATO) peak remains equally small in both spectra, also indicating that there is no significant disorder. However, the peak position for the film is 0.7 $\mathrm{cm}^{-1}$ lower than for the bulk sample, because the epilayer is stressed. Raman methods can easily detect and measure such small changes in peak position. (See Sec. 7.5, Applications Refs., Freundlich, Neu, Leycuras, Carles, and Verie (1988), fig. 1,
p. 252.)

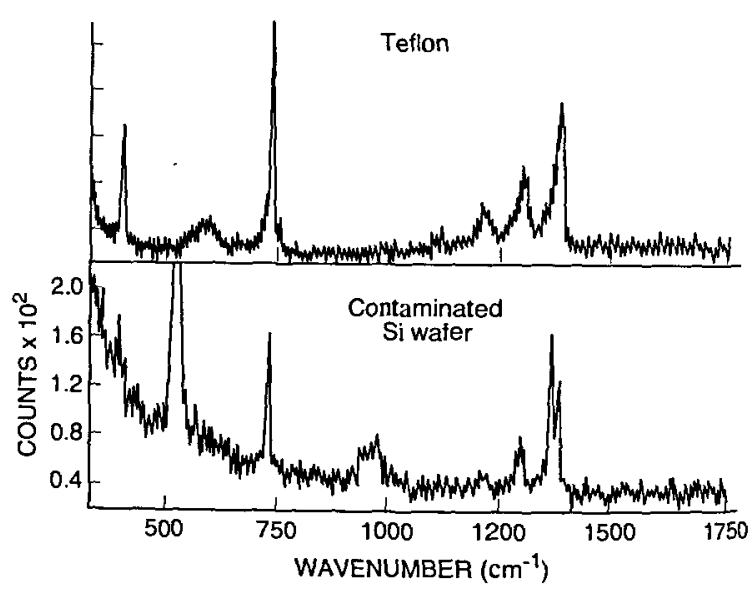

Fig. 22. Raman microprobe spectrum of a silicon wafer with surface contamination (lower plot) compared to the Raman spectrum of polytetrafluorethylene or teflon (upper plot). The peaks in the lower spectrum at $520 \mathrm{~cm}^{-1}$ and $950 \mathrm{~cm}^{-1}$ are known phonon modcs for silicon. The additional peaks arise from the contaminant. They resemble the teflon spectrum and suggest that the contamination came during wafer processing, which included polishing in a slurry containing organic solvents, and etching in a $\mathrm{CF}_{4} / \mathrm{H}_{2}$ plasma. Polymer could have been deposited on the wafer either as teflon from a container holding the slurry, or during the plasma etch. (Sec Sec. 7.5, Applications Refs., Adar (1986), fig. 2, p. 234.)

\section{General}

Light Scattering in Solids I. Introductory Concepts, M. Cardona, ed., Springer-Verlag, Berlin (1983).

Light Scattering in Solids 1I. Basic Concepts and Instrumentation, M. Cardona and G. Guntherodt, eds., Springer-Verlag, Berlin (1982).

G. J. Exarhos, Molecular characterization of dielectric films by laser Raman spectroscopy, in Characterization of Semiconduetor Materials, G. E. McGuire, ed., Noyes, Park Ridge, New Jersey (1989) pp. 242-288.

J. Geurts and W. Richter, Raman scattering from interface regions; structure, composition, and electron ic properties, in Semiconductor Interfaces: Formation and Properties, G. Le Lay, J. Derrien, and N. Boccara, eds., Springer-Verlag, Berlin (1987) pp. 328-334.

R. J. Nemanich, Raman spectroseopy for semiconductor thin film analysis, in Materials Characterization, Materials Research Society Symposia Procecdings Vol. 69, N. Cheung and M-A. Nicolet, eds., Materials Research Society, Pittsburgh, Pennsylvania (1986) pp. 23-37.

J. Sapriel, Raman characterization of semiconductor superlattices, in Spectroscopic Characterization Techniques for Semiconductor Technology III, Proceedings SPIE Vol. 946, O. J. Glembocki, F. H. Pollak, and F. Ponce, eds., SPIE, Bellingham, Waslington (1988) pp. 136-145. 
Table 7. Raman spectroscopy sensitivity. Given are sensitivities for the measurement of stress; $\sigma$; erystallinity; surface damage; horon 11 concentration, [ $\mathrm{B}^{11}$ ]; temperature; composition; substitutional carbon eoneentration, $\mathrm{C}_{\mathrm{a}}$; substitutional zine conecntration, $\mathrm{Zn}_{\mathrm{a}}$; builtin potential, $V_{\mathrm{bi}}$; and composition, $x$. The notations used for the measured quantity column are frequency of the LO phonon, cho); frequency of the TO phonon, $\omega_{T}$; crystallite diameter, $L$; intensity at a given energy, $I\left(2000 \mathrm{~cm}^{-1}\right)$; frequency, ( $\left.\omega\right)$, frequency shift, $\Delta \omega$; intensity of the two LO mode, $I(2 \mathrm{LO})$; intensity of the TO mode, $I_{\mathrm{TO}}$; intensity of the LO mode, $I_{\mathrm{LO}}$ or $/$ (LO); intensity of the Lplasmon branch, $I\left(\mathrm{~L}^{-}\right)$; intensity of the anti-Stokes peak, $I_{\mathrm{AS}}$; and intensity of the Stokes piak, $I_{\mathrm{S}}$

\begin{tabular}{|c|c|c|c|c|c|c|}
\hline Method & Matrix & Quantity & $\begin{array}{l}\text { Measured } \\
\text { quantity }\end{array}$ & Conversion & Sensitivity* & $\begin{array}{c}\text { Ref. } \\
\text { (see below) }\end{array}$ \\
\hline RS & $\mathrm{Si}$ & Stress & aro & $\sigma=\left(2.49 \times 10^{10} \mathrm{~Pa}^{-1}\right) \times \Delta \omega$ & $\pm 1 \times 10^{\prime} \mathrm{Pa}$ & 1 \\
\hline RS & Si & Crystallinity & $\begin{array}{c}L \\
@ 300 \mathrm{~K}\end{array}$ & Ref. 2 & & 2 \\
\hline RS & $\mathrm{Si}$ & Surface damage & $I\left(2000 \mathrm{~cm}^{-1}\right)$ & Ref. 3 & & 3 \\
\hline RS & $\mathrm{Si}$ & {$\left[\mathrm{B}^{11}\right]$} & $I\left(620 \mathrm{~cm}^{-1}\right)$ & Ref. 4 & & 4 \\
\hline RS & $\mathrm{Si}$ & Temperature & $\omega$ and $\Delta \omega$ & Ref. 5 & & 5 \\
\hline RS & $\mathrm{Si}_{x} \mathrm{Ge}_{1-x}$ & $x$ & $\omega$ & Ref. 6 & & 6 \\
\hline RS & GaAs & Crystallinity & $\stackrel{L}{L} \underset{300 \mathrm{~K}}{ }$ & Ref. 7 & & 7 \\
\hline RS & GaAs & Crystallinity & $\begin{array}{c}I(2 \mathrm{LO}) / I(540) \\
@ 300 \mathrm{~K}\end{array}$ & Ref. 8 & & 8 \\
\hline RS & GaAs & Crystallinity & $\begin{array}{l}I_{\mathrm{TO}} I_{\mathrm{LO}} \\
@ 300 \mathrm{~K}\end{array}$ & Ref. 9 & & 9 \\
\hline ERS & GaAs & $\mathrm{C}_{\mathrm{s}}, \mathrm{Zn}_{\mathrm{s}}$ & $\begin{array}{l}I\left(148 \mathrm{~cm}^{-1}\right) \\
I\left(174 \mathrm{~cm}^{-1}\right) \\
6 \mathrm{~K}\end{array}$ & Ref. 10 & $<1 \times 10^{19} \mathrm{~cm}^{-3}$ & 10 \\
\hline RS & GaAs & $V_{\mathbf{b i}}$ & $I(\mathrm{LO}) / I\left(\mathrm{~L}^{-}\right)$ & Ref. 11 & $\pm 0.2 \mathrm{~V}$ & 11 \\
\hline RS & $\mathrm{Al}_{x} \mathrm{Ga}_{1-x} \mathrm{As}$ & $x$ & $\omega_{L} \mathrm{O}$ & $\begin{array}{c}\left(\omega_{2} / 2 \pi c\right) / \mathrm{cm}^{-1}= \\
292.4+70.8 x-26.8 x^{2}-41.13 x^{3}\end{array}$ & $\pm 0.01 x$ & 12 \\
\hline RS & GaAs & Temperature & $\omega_{\text {Lo }}, \omega_{\text {ro }}$ & $l_{\wedge} J_{5}$ & $\pm 20^{\circ} \mathrm{C}$ & 13 \\
\hline
\end{tabular}

- Calculated as the concentration-equivalent-of-noise or unecrtainty in frequency.

\section{References}

[1] Th. Englert, G. Abstreitcr, and J. Pontcharra, Solid-State Electronies 23, 31 (1980).

[2] H. Richter, Z. P. Wang, and L. Ley, Solid Statc Commun. 39, 625, 1981; E. Bustarret, M. A. Hachicha, and M. Bruncl. Appl. Phy Lett. 52, 1675 (1988).

[3] J. C. Tsang, G. S. Oehrlein, I. Haller, and J. S. Custer, Appl. Phys. Lett. 46, 589 (1985).

[4] P. T. T. Wong and M. Simard-Normandin, J. Electrochem. Soc. 132, 980 (1985).

[5] H. Tang and I. P. Herman, Phys. Rev. B43, 2299 (1991).

[6] W. J. Brya, Solid State Commun. 12, 253 (1973); J. B. Renueci, M. A. Renucci, and M. Cardona, Solid State Commun. 9. 16\$1 (1971).

[7] K. K. Tiong, P. M. Armitharaj, F. H. Pollak, and D. E. Aspnes, Appl. Phys. Lett. 4, 122 (1983); P. Parayanthal and F. II. Pollak.

Phys. Rev. Lett. 52, 1822 (1984).
[8] J. Wagner and Ch. Hoffman, Appl. Phys. Lett. 50, 682 (1987); J. Wagncr and

[9] W. M. Duncan, R. J. Matyi, and H.-Y. Liu, Appl. Phys. Lett. 57, 163 (1994 (1986).

[10] J. Wagner, H. Seelcwind, and U. Kaufmann, Appl. Phys. Lctt. 48, 1054 (1981) (1987).

[11] L. A. Farrow, C. J. Sandroff, and M. C. Tamargo, Appl. Phys. Letl. Sl, Adachi. J. Appl. Phys. 58, RI (1985).

[12] O. K. Kim and W. G. Spitzer, J. Appl. Phys. 50, 4362 (1979); S. Ad

[13] J. R. Shealy and G. W. Wicks, Appl. Phys. Lett. 50, 1173 (1987) 
B. Schrader, Possibilities and limitations of FT-Raman spectroscopy, in Practical Fourier Transform Infrared Spectroscopy, J. R. Ferraro and K. Krishnan, eds., Academic Press, San Dicgo, California (I990) pp. 167-202.

\section{Applications}

F. Adar, Application of the Raman microprobc to analytical problems of microelectronics, in Microelectronic Processing: Inorganic Materials Characterization, ACS Symposia Scrics 295, L. A. Casper, ed., American Chemical Society, Washington, DC (1986) pp. 230-239.

F. Adar, Developments of the Raman microprobe instrumentation and applications, Microchemical Journal 538, pp. 50-79 (1988).

P. M. Amirtharaj, K-K. Tiong, and F. H. Pollak, Raman scattering in $\mathrm{Hg}_{0 . .} \mathrm{Cd}_{0.2} \mathrm{Te}$, J. Vac. Sci. Technol. Al, 1744 (1983).

S. J. Chang, M. A. Kallel, K. L. Wang, and R. C. Bowman, Strain distribution of MBE grown $\mathrm{GcSi} / \mathrm{Si}$ layers by Raman scattering, in Spectroscopic Characterization Techniques for Semiconductor Technology III, Proceedings SPIE Vol. 946, O. J. Glembocki, F. H. Pollak, and F. Ponce, eds., SPIE, Bellingham, Washington (I988) pp. 163-168.

Z. C. Feng, S. Perkowitz, and O. Wu, Raman and resonant Raman scattering from the $\mathrm{HgTe} / \mathrm{CdTe}$ superlattice, Phys. Rev. B 41, 6057-6060 (I990).

Z. C. Fcng, S. Perkowitz, T. S. Rao, and J. B. Webb, Raman characterization of $1 \mathrm{nSb} / \mathrm{GaAs}$ grown by metalorganic magnetron sputtering, in Layered Structures: Heteroepitaxy, Supcrlattices, Strain, and Mctastability, Materials Research Society Symposia Proceedings Vol. 160, B. D. Dodson, L. J. Schowalter, J. E. Cunningham, and F. H. Pollak, eds., Materials Research Society, Pittsburgh, Pennsylvania (1990) pp. 739-744.

Z. C. Feng, S. Perkowitz, T. S. Rao, and J. B. Webb, Resonance Raman scattcring from epitaxial InSb films grown by metalorganic magnetron sputtering, J. Appl. Phys. 68, 5363-5365 (1990).

A. Freundlich, G. Neu, A. Leycuras, R. Carles, and C. Verie, Hcterogencous strain relaxation in GaAs on Si (100), in Hcteroepitaxy on Silicon: Fundamentals, Structure, and Devices, Matcrials Research Socicty Symposia Proceedings Vol. 116, H. als Research Sol, H. Ishiwara, and R. J. Nemanich, eds., Materj256.

J. Gonzalez-Hernandez, D. Martin, and R. Tsu, Raman study of strain and microadhesion in silicon, in Spectroscopic Characterization Techniques for Semiconductor Technology, Procecdings SPIE Vol. 452, F. H. Pollak and R. S. Bauer, cds., SPIE, Bellingham, Washington (1983) pp. 44-50.

D. Kirillov, P. Ho, and G. A. Davis, Raman scattering study of mixing of GaAs/AlAs superlattices by ion implantation and rapid thermal anncaling, in Materials Characterization, Materials Rescarch Society Symposia Proceedings Vol. 69, N. Cheung and Pennsylvania (1986) pp. 185-190.
D. S. Knight and W. B. White, Characterization of diamond films by Raman spectroscopy, J. Mater. Res. 4, 385-393 (1989).

P. Lao, W. C. Tang, A. Madhukar, and P. Chen, Alloy disorder effects in molecular beam epitaxially grown AIGaAs examined via Raman and Rayleigh scattering and near edge luminescence, in Spectroscopic Characterization Techniques for Semiconductor Tcchnology III, Proceedings SPIE Vol. 946, O. J. Glembocki, F. H. Pollak, and F. Ponce, eds., SPIE, Bellingham, Washington (1988) pp. I50-154.

J. Menendez, A. Pinczuk, J. P. Valladares, L. N. Pfeiffer, K. W. West, A. C. Gossard, and J. H. English, Resonance Raman scattering in short period GaAs-AlAs supcrlattices, in Spectroscopy of Semiconductor Microstructures, G. Fasol, A. Fasolino, and P. Lugli, eds., Plenum Press, New York (1989) pp. I57-164.

S. Nakashima and M. Hangyo, Characterization of semiconductor materials by Raman microprobc, IEEE J. Quantum Electron. QE-25, 965-975 (1989).

R. J. Nemanich, D. K. Biegelsen, R. A. Street, B. Downs, B. S. Krusor, and R. D. Yingling, Strain in graded thickncss $\mathrm{GaAs} / \mathrm{Si}$ heteroepitaxial structures grown with a buffer layer, in Heteroepitaxy on Silicon: Fundamentals, Structure, and Devices, Materials Research Socicty Symposia Procecdings Vol. 1I6, H. K. Choi, R. Hull, H. Ishiwara, and R. J. Nemanich, eds., Matcrials Research Society, Pittsburgh, Pennsylvania (1988) pp. 245250 .

R. J. Nemanich, R. W. Fiordalice, and H. Jeon, Raman scattering characterization of titanium silicide formation, IEEE J. Quantum Electron. QE-25, 997-1002 (1989).

G. D. Pazionis, H. Tang, and I. P. Herman, Raman microprobe analysis of tempcrature profiles in $\mathrm{CW}$ laser heated silicon microstructures, IEEE J. Quantum Electron. QE-25, 976-987 (1989).

L. S. Plano and F. Adar, Raman spectroscopy of polycrystalline diamond films, in Raman and Luminescence Spectroscopy in Technology, Procecdings SPIE Vol. 822, J. E. Griffiths and F. Adar, eds., SPIE, Bellingham, Washington (1987) pp. 52-56.

C. J. Radens, B. Roughani, H. E. Jackson, J. T. Boyd, and R. D. Burnham, Raman microprobe analysis of strain induced by patterned dielectric films on GaAlAs structures, IEEE J. Quantum Electron. QE-25, 989-992 (1989).

B. Roughani, J. J. Jbara, J. T. Boyd, T. D. Mantei, and H. E. Jackson, Reactive ion etching of MBE GaAs; a Raman scattering study, in Spectroscopic Charactcrization Techniques for Semiconductor Technology III, Proceedings SPIE Vol. 946, O. J. Glembocki, F. H. Pollak, and F. Ponce, eds., SPIE, Bellingham, Washington (1988) pp. 146-149.

B. Roughani, H. E. Jackson, J. J. Jbara, T. D. Mantcl, G. Hickman, C. E. Stutz, K. R. Evans, and R. L. Jones, Raman scattering studies of reactive ion-etched MBE (100) n-type GaAs, IEEE J. Quantum Electron. QE-25, 1003-1007 (1989).

J. C. Tsang and S. S. Iycr, Raman spectroscopy and the characterization of buricd semiconductor layers, IEEE J. Quantum Electron. QE-25, 1008-1011 (1989). 
J. Wagner and M. Ramstener, Raman spectroscopic assessment of $\mathrm{Si}$ and $\mathrm{Be}$ local vibrational modes in GaAs layers grown by molecular beam epitaxy, IEEE J. Quantum Electron. QE-25, 993-996 (1989).

About the authors: Sidney Perkowitz is a Charles Howard Candler Professor of Condensed Matter Physics at Emory University and Walter M. Duncan is a senior member of the Technical Staff at Texas Instruments. David G. Seiler is Leader of the Materials Technology Group in the Semiconductor Electronics Division of the NIST Electronics and Electrical Engineering Laboratory. The National Institute of Standards and Technology is an agency of the Technology Administration, U.S. Department of Commerce. 